\title{
Perspectivas de padres y madres ecuatorianos sobre el contrato pedagógico entre la institución escolar y la familia en un contexto migratorio
}

María Fernanda Moscoso ${ }^{1}$

RESUMEN

LAS SUBJETIVIDADES (ESCOLARES) DE NIÑOS/AS Y JÓVENES SE RELACIONAN CON SU PAPEL COMO ESTUDIANTES Y, POR TANTO, ESTÁN ATRAVESAdAS POR VEREdictos QUE SE MIDEN POR MEdo del Éxito ESCOLAR. El ÉXITO ESCOLAR DEBE SER COMPRENDIDO SEGÚN LAS DIFERENTES RELACIONES QUE SE TEJEN ENTRE LOS VEREDICTOS FAMILIARES Y LOS ESCOLARES, LOS CUALES DEPENDEN EN GRAN MEDIDA DE LAS DIFERENTES REPRESENTACIONES QUE SE HACEN LOS Distintos ACTORES SOBRe EL CONTRATO PEDAGógICO. LA PRESENTE PROPUESTA SE INSCRIBE EN ESTE TERRENO CON EL OBJETO DE EXPLORAR LAS PERCEPCIONES ELABORADAS POR UN GRUPO DE PADRES Y MADRES ECUATORIANOS SOBRE LA PARTICIPACIÓN dE SUS hIJOS/AS EN EL SISTEMA DE ENSEÑANZA ESPAÑOL. El TRABAJO CONSIDERA TRES ASPECTOS: UNA BREVE CARACTERIZACIÓN DEL TRAYECTO MIGRATORIO FAMILIAR, UNA PRESENTACIÓN DE LAS IDEAS ACERCA DE LA EDUCACIÓN DE LOS HIJOS EN UN CONTEXTO TRASNACIONAL Y UN ANÁLISIS DE LOS DISCURSOS SOBRE ALGUNOS FACTORES DECISIVOS EN LAS TRAYECTORIAS ESCOLARES DE LOS NIÑOS/AS Y JÓVENES COMO EL APOYO ESCOLAR, LA PARTICIPACIÓN DE PAPÁS Y MAMÁS EN LA INSTITUCión, LOS CRITERIOS PARA LA ELECCIÓN DE LA ESCUELA Y LAS EXPECTATIVAS familiares. Se sostiene la idea de QUe la ACTITUd de los PRogenitores hacia la ESCUELA, EN LUGar de SER CHOCANTE O INCOMPATIBLE, LE CONFIERE LEGITIMIDAD PUES REAFIRMA LAS BASES EN LAS CUALES SE ASIENTA.

Palabras clave: Familia - Escuela - Migración - Contrato pedagógico - Cultura legítima.

\section{Abstract}

The (SCHOOL) SUBJECTIVITIES OF CHILDREN AND YOUNG PEOPLE ARE RELATED TO THEIR ROLE AS STUDENTS AND, THEREFORE, THEY ARE CROSSED BY VERDICTS THAT ARE MEASURED BY THE SCHOOL SUCCESS. THE SCHOOL SUCCESS SHOULD BE UNDERSTOOD AS THE VARIOUS RELATIONSHIPS CONSTRUCTED AMONG THE FAMILIAR AND ACADEMICAL VEREDICTS, WHICH DEPEND LARGELY ON THE REPRESENTATIONS MADE BY DIFFERENT ACTORS AROUND THE PEDAGOGICAL CONTRACT. The AIM OF THIS PROPOSAL IS TO EXPLORE THE PERCEPTIONS DEVELOPED BY A GROUP OF ECUADORIANS PARENTS AROUND THE PARTICIPATION OF THEIR CHILDREN IN THE SPANISH EDUCATIONAL SYSTEM. THE WORK CONSIDERS THREE ASPECTS: A BRIEF CHARACTERIZATION OF THE FAMILY MIGRANT JOURNEY, A PRESENTATION OF THE IDEAS ABOUT THE EDUCATION OF CHILDREN IN A TRANSNATIONAL CONTEXT AND AN ANALYSIS OF THE DISCOURSES ON SOME KEY FACTORS IN THE ACADEMIC TRAJECTORIES OF CHILDREN AND YOUNG PEOPLE AS THE SCHOOL SUPPORT, THE PARTICIPATION OF THE PARENTS IN THE INSTITUTION, THE CRITERIA FOR THE ELECTION OF THE SCHOOL AND THE FAMILY EXPECTATIONS. I SUPPORT THE IDEA THAT THE ATTITUDE OF THE PARENTS TOWARD SCHOOL, INSTEAD OF BEING SHOCKING OR INCOMPATIBLE, CONFERS LEGITIMACY BECAUSE REAFFIRMS THE BASES IN WHICH IT STANDS.

Keywords: Family - School - Migration - Pedagogical contract - Legitimate culture.

1 Doctoranda Antropología Social. Freie Universität Berlin. Lateinamerika-Institut. Rüdesheimer Str. 54-56.D-14197 Berlin.mfmoscoso1@yahoo.es 


\section{Introducción}

menudo, la vida escolar de los niños y jóvenes se desarrolla en medio de las relaciones
que tienen lugar entre los veredictos de la institución escolar y los de sus familias. Sin
embargo, ni la escuela ni la familia son instituciones uniformes y homogéneas por dos motivos: (1) A ellas se suscriben diferentes miembros con disímiles trayectorias y perspectivas por lo que deberían ser abordadas como espacios de puntos de vista en los cuales los discursos se construyen en relación con otros por medio de conexiones estructurales en torno a problemáticas comunes; (2) La escuela y la familia se hallan ubicadas en el cruce de esferas locales, nacionales y globales que inciden de modo más o menos directo en su funcionamiento.

En el espacio escolar y el espacio familiar circulan perspectivas y percepciones de las que destacan aquellas que son elaboradas por el mundo adulto, en concreto, por profesores y progenitores. No sólo que de las relaciaiones cotidianas de los chicos y chicas, aquellas que desarrollan con maestros y profesoras y la familia (y los pares) son fundamentales, sino que además, estas tienen un papel central en la transmisión y formación de los capitales sociales, escolares y culturales y, por tanto, en la configuración de sus subjetividades.

Las subjetividades (escolares) de chicos y chicas se relacionan con su papel como estudiantes y, por tanto, están atravesadas por veredictos que se miden por medio del éxito escolar. El éxito escolar debe ser comprendido, por lo tanto, según las diferentes relaciones que se tejen entre los veredictos familiares y los escolares. Estas relaciones, como señala Bourdieu (1999), dependen en gran medida de la representación muy variable según las categorías sociales que las familias se hacen del "contrato pedagógico" y que difieren a la vez en el grado de confianza que se deposita en la escuela y los maestros y el de la comprensión de sus exigencias explícitas y sobre todo implícitas.

El presente artículo se inscribe en esta temática con el objeto de explorar las percepciones elaboradas por un grupo de padres y madres a propósito de la participación de sus hijos/as en el sistema escolar en un contexto migratorio. En efecto, si la migración modifica y transforma la organización familiar, estos arreglos impactan de modo directo en los trayectos escolares de niños/as y jóvenes. Entre la escuela y la familia se teje un entramado de relaciones de tal modo que al cambiar la segunda, estas relaciones también lo hacen. El objetivo del presente artículo es, por tanto, indagar en los discursos de padres y madres inmigrantes ecuatorianos sobre el "contrato pedagógico" en el contexto migratorio español.

El análisis considera tres aspectos: una breve caracterización del trayecto migratorio famliar (ecuatoriano), una presentación de las representaciones de los progenitores sobre de la educación de sus hijos/as en un contexto migratorio y un análisis de los discursos sobre algunos factores decisivos en las trayectorias escolares de los niños/as y jóvenes como el apoyo escolar, la participación de papás y mamás en la institución, los criterios para la elección de la escuela y las expectativas familiares. ¿Qué quiere decir esto? Varias cosas, como que habría que preguntarse por la interpretación que papás y mamás hacen de sus roles como tales, por el lugar de los hijos en la familia y el papel de su educación y por supuesto, sobre las instituciones educativas en las que sus hijos participan: ¿cómo se entiende la educación de los hijos?, ¿qué criterios se han tomado en cuenta en el momento de elegir un centro educativo u otro?, ¿cómo es el instituto?, ¿cómo son los profesores?, ¿qué significa participar?, etc.

Las corrientes teóricas que analizan la relación entre las familias/comunidades y la escuela parten de un hecho: la diferencia. Parece de común acuerdo la idea de que existe una incompatibilidad la cual, según el esquema desarrollado por Jociles (2006) se explica de distintos modos según el modelo: en el desajuste de contenidos (modelos del multiculturalismo), 
de estilos de comunicación/interacción (modelo sociolingüístico), de formas de relacionarse con el saber entre la escuela y el medio sociocultural de los alumnos (modelo de la cultura legítima), en las estrategias sociales y económicas desplegadas con respecto a la escuela por cada minoría o colectivo en función de la estructura de oportunidades existentes en la sociedad (modelo ecológico). Este trabajo se inscribe en el modelo de la cultura legítima, perspectiva desarrollada por Bernard Lahire (2000) y Franzé (2003) en España según la cual la escuela exige a los grupos minoritarios o de clases bajas competencias que no tienen y/o entran en contradicción con las de la institución. En este caso, la atención se centra en las competencias de padres y madres de familia las cuales adquieren unas formas u otras en función de los requerimientos del nuevo contexto escolar y sus experiencias y conocimientos propios.

Lo anterior quiere decir que, al igual que sus hijos -que ya han asistido a la escuela en el país de origen, que han mantenido determinado tipo de relaciones con los profesores, que han hecho tareas y que en su día fueron sujetos de expectativas escolares determinadas-, papás y mamás han desarrollado una serie de conocimientos, saberes y herramientas que pueden o no ser compatibles con los requerimientos de las instituciones en España. Además, los progenitores, no sólo han acumulado de modo previo experiencias sobre el papel de sus hijos e hijas como estudiantes, su rol en el proceso educativo y su relación con la institución educativa, sino que, además, ellos mismos han atravesado por un proceso educativo, es decir que, han desarrollado experiencias previas que se ajustan a su propio trayecto escolar y que hoy en día inciden de modo directo en la elaboración de representaciones, ideas y prácticas. Los padres y madres, al igual que sus hijos, no llegan vacíos de conocimientos y experiencias escolares. Algo obvio a primera vista, pero que a veces parece necesario recordar.

Así, los discursos valoran la educación de los hijos, asientan la autoridad del profesor, la separación entre las familias y la escuela, la prevalencia de la cultura escolar sobre la falta de la misma, etc. Lo cual, lejos de reafirmar la percepción común de que existe una suerte de "choque cultural" entre los padres y madres migrantes y la escuela, más bien, indica todo lo contrario. Por lo señalado, se sostiene la idea de que la actitud de los progenitores hacia la escuela, en lugar de ser chocante o incompatible, le confiere legitimidad pues reafirma las bases en las cuales se asienta.

El límite de este trabajo radica en dos cuestiones. Por un lawdo, al trabajar con material discursivo, habría que recolectar observaciones sobre las prácticas, tanto en el espacio familiar/ comunitario como en el escolar. Por otro, si bien se podría hablar de discursos que se adecuan a los requerimientos de las instituciones educativas, este hecho sigue sin explicar la alta tasa de deserción y fracaso escolar de las minorías. De todos modos, nos tomamos el riesgo de afirmar que en este análisis se ha de entender que las relaciones entre la familia/comunidad y la escuela tienen varias formas que se entremezclan entre sí: la ausencia de valores y conductas compatibles con la escuela, la incompatibilidad entre uno y otro y la presencia de valores y conductas legitimadoras.

Esta investigación forman parte de un proyecto más amplio desarrollado durante los años 2005-2008 titulado Adolescentes inmigrantes en la ESO financiado por el Ministerio de Ciencia e Innovación español (Referencia: SEJ2005-08371/SOCI). En la segunda fase del proyecto se ha realizado un estudio etnográfico multidimensional del un centro de educación secundaria situado en el sur de la ciudad de Madrid durante dos cursos académicos (2007-08 y 200809). En lo concerniente a los resultados presentados en este artículo, se ha hecho un estudio cualitativo puesto que el levantamiento de la información se llevó a cabo a través de entrevistas a profundidad dirigidas a padres y madres de familia de origen ecuatoriano cuyos hijos asisten al instituto. Los criterios al elegir a los informantes han respondido a las propias necesidades de la investigación, es decir, que sean padres y madres cuyos hijos asisten al instituto objeto del estudio multidimensional y, en este caso, que sean originarios de Ecuador puesto que se trata de uno de colectivos latinoamericanos más representativos en España, el más numeroso en la institución y el grupo de interés de la tesis doctoral que me hallo desarrollando. Un tercer criterio 
ha sido el que los hijos de las informantes no hayan nacido en España, es decir, que formen parte de la generación de hijos de migrantes que han nacido y vivido sus primeros años en el país de origen y que luego han viajado, siendo aún niños o adolescentes, al país de acogida.

El material con el que se ha trabajado es discursivo. Se ha llevado a cabo una interpretación que contempla dos cuestiones que se interrelacionan entre sí. Por una parte, se ha considerado que el análisis de los discursos sobre las prácticas y las experiencias escolares de padres y madres migrantes en torno a la escolarización de sus hijos ha de ser transnacional. En otras palabras, entendemos que los discursos se construyen atravesados por un proceso de movilidad social, es decir, constituyen un flujo de representaciones en las cuales se pone en juego ideas, principios, creencias y valores en el que el aquí y el allí, el ahora y el pasado se entremezclan en un contexto transnacional. Esto quiere decir que los conocimientos sobre el medio no pueden ser separados entre aquellos que pertenecen al lugar de origen y el contexto actual, sino que se interrelacionan unos con otros, generando un flujo de representaciones. El modo de entender el presente no puede ser comprendido sin una atención en las formas en las que el pasado actúa sobre el mismo y viceversa. Así, cuando papás y mamás elaboran discursos en torno al contrato pedagógico llevan a cabo un acto de memoria. La indagación del pasado, desde esta perspectiva, no puede ser separada de las circunstancias del presente, dado que recordar implica elaborar puntos de vista sobre determinados asuntos: al rememorar, los seres humanos no elaboraríamos únicamente un acto de comprensión del tiempo (pasado, presente, futuro), sino también de la realidad, de nuestro posicionamiento y del lugar de los otros en la misma. Por lo dicho, los discursos de papas y mamás han sido analizados desde una perspectiva biográfica, es decir como memoria discursiva (Pazos, 2002; Moscoso, 2009a).

\section{Los trayectos migratorios familiares. Breves caracterizaciones.}

Una de las primeras cuestiones que habría que abordar al hablar sobre las percepciones de padres y madres con respecto a la educación de sus hijos e hijas en un contexto migratorio, tiene que ver con la propia idea de familia. En efecto, cabe destacar que aquello que se suele abordar como el trayecto migratorio familiar no es necesariamente un camino homogéneo. Se trata más bien de un proceso que se puede dividir, con fines analíticos, en dos niveles: por un lado están los trayectos individuales que se cruzan entre sí en momentos y espacios determinados y en un segundo nivel se halla la trayectoria grupal, es decir, la participación de cada uno de los miembros en función de su pertenencia a un grupo más amplio: la familia. Y a su vez, a la relación entre el grupo y otras estructuras de la sociedad.

Con respecto al primer nivel, se debería anotar que no se puede llevar a cabo un análisis de los discursos y experiencias de los miembros de las familias sin atender a la heterogeneidad que los caracteriza: el país, la región, la adscripción étnica, la clase social. Luego, en un segundo nivel tendría que atenderse a las diferencias entre sus miembros en función de criterios como el género, la edad, lugar de nacimiento, perfil educativo.

Estos elementos confluyen, se cruzan e inciden en el modo por el cual cada miembro de la familia ocupa una posición en el grupo, en las redes más amplias y en diversos espacios, como el escolar. Allí, en la familia y en la escuela, las relaciones entre los miembros son, en sí mismas, relaciones de poder, están sujetas a diferencias y desigualdades y no son neutras. El modo por el cual esas desigualdades y diferencias adquieren formas y se concretan, es una de las claves en el acercamiento que se lleva a cabo.

La migración de ecuatorianos hacia España es heterogénea -multiclasista, multiétnica, de varias generaciones-, sin embargo, en lo concerniente a las familias, existen ciertas cuestiones y características comunes que se anotan a continuación. 
En general, la mayoría de los padres y madres entrevistados han llegado a España a partir del año $1999^{2}$ y formaban parte, en Ecuador, de familias ampliadas o extensas -organización muy frecuente en las zonas rurales y entre ciertos sectores en el área andina-. La familia ampliada o extensa es aquella donde participan dos o más generaciones, sus integrantes mantienen lazos de consanguinidad (padres/madres, hijos/as, nietos/as, primos) y afinidades (nueras, yernos, cuñado, etc.). También pueden formar parte de la familia individuos que mantienen lazos de parentesco simbólico (ahijados/as, por ejemplo). En su interior cada miembro asume determinadas responsabilidades y derechos, dependiendo de su posición dentro de la estructura familiar. En Ecuador, este tipo de familia representa el $46 \%$ de los agrupamientos familiares (CEPLAESBM, 2005). No obstante su importancia previa -como anotan Camacho y Hernández (2007)- la familia ampliada o extensa, al igual que otras formas de organización familiar, han cobrado mayor relevancia a propósito del fenómeno migratorio. De hecho, en términos cuantitativos, la estructura ampliada es más común en las familias (52\%) migrantes que en el promedio nacional.

Ahora bien, los planteamientos de varios autores (Herrera, 2005; Meñaca, 2005, Lagomarsino, 2005, Herrera y Martínez, 2002, Pribilsky, 2001, Camacho y Hernández, 2007) sugieren dos cosas: (1) la migración no es un factor de descomposición familiar ${ }^{3}$; (2) aunque sí representa un cambio en la estructura familiar. Camacho y Hernández (2007) describen al menos tres modalidades de organización familiar -en cuyo interior se presentan variaciones o submodalidades- que cobran fuerza a partir de la migración de sus miembros:

1. Las monoparentales (con jefatura femenina o masculina). Se subdividen entre aquellas que sostienen un proyecto de vida en común y aquellas que viven un proceso de ruptura conyugal.

2. Las familias constituidas solamente por hermanos y hermanas, en donde la responsabilidad recae sobre los mayores quienes se hacen cargo de los más pequeños.

3. La familia ampliada o extensa que asume el rol de "familia tutora" de la prole que ha quedado. Normalmente son familias cuya jefatura está a cargo de la abuela y/o el abuelo. Estas familias, a su vez, también pasan por un proceso de reestructuración al acoger a nuevos miembros.

2 La crisis económica, que se desata con mayor fuerza en Ecuador a partir de 1999, acelera el proceso migratorio, diversifica el perfil de las personas que migran y se extiende al resto del país, sobre todo en las zonas urbanas, aumentando en una magnitud sin precedentes. Los destinos también se diversifican, apareciendo España como un nuevo polo importante. Hasta 1997, el 63\% de los emigrantes se dirigió a Estados Unidos, pero el censo de 2001 demuestra un giro importante en el lugar de destino. De las personas que salieron entre 1996 y 2001 , el $49 \%$ lo hizo a España, el 27\% a Estados Unidos y el 10\% a Italia. La migración a España pasa de menos de 11.000 personas en 1997 a 157.579 en 2002 (Dirección Nacional de Migración). De acuerdo con el censo de 2001, 6.378.000 ecuatorianos habrían migrado en el período 1996-2001 (Herrera, 2005;151).

3 Dos cosas se pueden señalar al respecto. En primer lugar, que no fue sino con el rápido crecimiento de emigración femenina que los discursos políticos, de la iglesia, mediáticos y sociales se erigieron alrededor del supuesto resquebrajamiento familiar y el abandono-culpabilizador de las madres/esposas. Sin embargo, como señala Reyes (2002), en Ecuador existe un aumento progresivo de nuevas formas de familia como las monoparentales -forma que cuestiona la legitimidad del tradicional modelo del estado asistencialista, cuyo pilar fundamental se basa en la estabilidad de la familia nuclear bi-parental asimétrica con una estructura conyugal - heterosexual - nuclear, figura que implica la cohabitación de padre, madre e hijos compartiendo una casa y que ve en esta composición familiar el "tipo-ideal"- y otras configuraciones nuevas y/o diferentes (familias disgregadas por separaciones o divorcios, uniones homosexuales, madres y padres adolescentes, etc.). Estas nuevas formas de familia ponen en entredicho tanto la creencia de que la migración de las mujeres es la causante de los cambios familiares, así como la misma idea de familia imperante en los imaginarios. 
La composición familiar no es de ningún modo constante, las formas descritas pueden cruzarse unas con otras, antecederse, mezclarse en el tiempo, desaparecer o transformarse. Existen disímiles modos de reagrupación en concordancia con diferentes etapas de desplazamiento. De hecho, al hacer una descripción más concreta de los trayectos familiares de los hombres y mujeres entrevistados, se pueden apreciar varias cosas. En primer lugar, estamos frente a familias reagrupadas cuyos miembros han estado separados geográficamente durante un período y se han reencontrado ${ }^{4}$. Desde la perspectiva de los niños y jóvenes que forman parte del trayecto migratorio familiar, las familias ha tenido que atravesar un proceso que puede ser descrito del siguiente modo (Moscoso, 2009): la partida (viaje de papá y/o mamá), la incertidumbre (el tiempo de espera y elaboración o acomodación a nuevos vínculos sociales y familiares), la doble partida (el viaje de los hijos, la ruptura con los espacios de socialización cotidianos), el reencuentro y el asombro (se refiere al período de descubrimiento y conocimiento de los nuevos espacios familiares, urbanos, domésticos, etc.) y la incorporación (el ingreso a la institución educativa). Estos momentos han supuesto una serie de transformaciones en las dinámicas familiares pues nos hemos encontrado con los siguientes casos: hijos que viajan con uno o con ambos padres, que son reagrupados o que permanecen en el país de origen.

Al tratarse de familias reagrupadas, los hijos e hijas alrededor de los cuales giran los discursos y las prácticas son fruto del reencuentro ${ }^{5}$, han sido "traídos" y por lo tanto, han estado los primeros años de su vida en Ecuador. Hablamos de chicos y chicas que han nacido en Ecuador, han pasado parte de su infancia allí y luego han viajado a España. Esto quiere decir, por lo señalado hasta el momento, que la mayoría de ellos han vivido inmersos en varias formas familiares y que muy probablemente, han sido escolarizados en su país de origen en una o varias instituciones educativas.

Otro elemento ha considerar en el análisis es la feminización de la migración ecuatoriana (y latinoamericana). Las mujeres han representado la primera piedra del proyecto migratorio familiar o son cabezas de hogar que comúnmente establecen lazos transnacionales de reproducción social con sus familias y comunidades de origen (Herrera, 2005). A partir de 1999, la migración hacia Europa -y España- se caracterizó por ser básicamente femenina. Las mujeres migraron ${ }^{6}$ como trabajadoras independientes o encabezando los proyectos migratorios de sus familias. Sin embargo, han sido alcanzadas progresivamente por los hombres.

En cuanto al perfil socioeconómico de las familias que migraron, de modo muy general se puede afirmar que de la información cuantitativa existente se desprende que el mayor porcentaje de los migrantes $(39 \%)$ proviene de hogares vulnerables ${ }^{7}$, mientras que la población pobre e indigente constituye menos de la tercera parte. Si se analizan los datos por sexo (Camacho y Hernández, 2007), se puede afirmar que el origen de la migración masculina es más pobre que la femenina, lo que concuerda con la mayor migración de hombres del sector rural; mientras

4 En algunos casos, la reagrupación aún es inconclusa, hay parejas e hijos que aún permanecen en Ecuador. Asimismo, la reagrupación no sólo ha significado traer a los hijos, hay casos en los que la familia en España, reagrupa al padre o madre del padre o la madre o a tíos o sobrinos. Y por supuesto, existen nuevos emparejamientos y rupturas.

5 La cantidad de niños, niñas y adolescentes cuyos progenitores migraron asciende de 17.000 a 150.000 entre 1999 y 2000 . El 36\% de mujeres y el 40\% de hombres que migraron dejaron a sus hijos/as menores de 18 años en el Ecuador, ya sea al cuidado de otra familia, al cuidado de hermanos mayores, etc...Más mujeres jefas de hogar (solteras, divorciadas o separadas) dejaron hijos/as menores de 18 años, que los hombres en iguales condiciones, lo que ha demandado la participación de otras mujeres de la familia. En promedio, cada ecuatoriano dejó 2 hijos/as menores al ausentarse del país. Para el año 2005, el total de niños, niñas y adolescentes con padre, madre o ambos progenitores migrantes asciende a 218.704 .

6 Estas mujeres se caracterizan por formar parte de cadenas de dimensiones transnacionales que, como explica Orozco (2008), se conforman con el objetivo de sostener cotidianamente la vida y en las que los hogares se transfieren trabajos de cuidados de unos a otros sobre la base de ejes de poder, entre los que cabe destacar el género, la etnia, la clase social, y el lugar de procedencia. Las cadenas globales de cuidados son, por tanto, un ámbito estratégico desde el que comprender los nexos migración-desarrollo a partir de una perspectiva de género.

7 Indigente: con consumo menor a la canasta de alimentos. Pobre: con consumo menor a la canasta básica de alimentos y servicios. Vulnerable: con consumo menor a 2 canastas básicas al mes. Y solvente: con consumo superior a 2 canastas básicas. (Camacho y Hernández, 2007). 
que en los estratos vulnerable y solvente, la emigración femenina es mayor. Se puede afirmar, por tanto, que la mayor emigración se produjo entre mujeres y hombres de los hogares medios bajos de los centros urbanos, estrato que fue especialmente afectado por la crisis, y que no fue objeto de ninguna política para paliar el deterioro de sus ingresos y de sus condiciones de vida. A la vez, son estos sectores los que pueden disponer de los recursos indispensables para realizar su éxodo.

Otro dato interesante es que los migrantes ecuatorianos de la última década presentan una escolaridad relativamente alta para la media nacional Al desagregar por sexo, se observa que las mujeres tienen un nivel educativo mayor que la de los hombres: mientras el 54,7\% de mujeres han cursado la educación media o secundaria, solo el $46 \%$ de hombres se ubican en ese grupo; el $16 \%$ de mujeres migrantes y el $15,1 \%$ de hombres han realizado estudios universitarios. En el grupo de quienes han realizado estudios superiores no universitarios y en el reducido grupo de quienes han accedido a estudios de post-grado, es mayor la presencia masculina (ENEMDU, 2000). Como señala Camacho y Hernández (2007), es interesante observar que en lo tocante al nivel educativo, existe la tendencia de que a mayor nivel educativo de los padres, se dejen menos hijos menores de edad, procurando llevarlos consigo el momento de la partida o buscando posteriormente la reunificación familiar, sobre todo cuando es la madre quien ha migrado.

Esta escueta caracterización de las familias de las que los niños/as y jóvenes forman parte tiene como objeto contextualizar los discursos de los padres y madres de familia - cada uno de los casos se describe en el Anexo I. No se ha de olvidar, sin embargo, que los efectos en la transformación de la organización familiar a propósito de la migración y su relación con el espacio escolar tiene particularidades por razones de género, edad, etnicidad, raza y clase social y que existe una infinitud de variables y factores a nivel local, nacional, regional y global que inciden directamente en los mismos. El alcance del presente acápite no logra abordar el fenómeno en toda su complejidad, sino que pretende arrojar algo de luz en una parte del mismo. A continuación se desarrolla un análisis de los discursos de papás y mamás a propósito de la educación de sus hijos/as.

\section{"Que no sean como nosotros": El sacrificio y los mandatos parentales}

En general, los discursos de papás y mamás sobre la educación de sus hijos, lejos de lo que se suele repetir con frecuencia -sobre todo por parte de los profesores y profesoras- denotan una alta valoración de la misma. En general, papás y mamás entienden que la educación formal de sus hijos es un valor añadido a su formación y que ir a la escuela sí es importante.

Por una parte, se relaciona el acceso a la escuela al ascenso social:

"Yo para mi hijo, lo mejor. Yo, que se dedique, como le hacemos ver. Que tenga un mejor futuro que el nuestro" (Carmen).

"La ilusión que tenemos nosotros como padres es que lleguen a ser algo, por algo me refiero a hacer una carrera, o sea, a estudiar, siempre les pedimos a ellos que estudien. Mientras nosotros les podamos dar los estudios, les daremos. También está en la cabeza de ellos si quieren estudiar, bueno, de momento sí están ilusionados y eso (...) nosotros como padres queremos que tengan una carrera, no se de qué, ellos mismos sabrán valorar y nosotros aspiramos y tenemos la ilusión de que sean alguien en la vida. No se qué, pero alguna cosa, que no sean como nosotros. Hemos acabado la primaria en Ecuador y como la mayor parte, hemos salido a trabajar. Con una carrera, alguna cosa, yo creo que les facilita la vida, yo creo que les facilita la carrera y tenemos que ayudarles. Tenemos la obligación de ayudarles en lo que podamos y estaremos ahí para eso. Nuestra aspiración es que 
sean alguien en la vida para que puedan trabajar aquí, allá, en otros países. Es como cualquier cosa que pediría el padre, que el hijo llegue a ser algo, que triunfe. Por eso los padres tienen que estar juntos, apoyarles en todo lo que haga falta y a ver qué pasa. Algo en la vida, una cosa buena" (Manuel).

Las esperanzas depositadas en la formación escolar de los hijos e hijas no es una novedad. Es común que padres y madres esperen que sus hijos tengan una vida mejor que ellos en varios aspectos: aquellos padres dueños de un capital a heredar esperan que sus vástagos reproduzcan su posición y aquellos que no tienen capital económico ni escolar a heredar, confían en la escuela como el espacio de adquisición de esos capitales, como en este caso. Esto es evidente en América Latina y en Ecuador en donde los logros en materia de acceso a la educación han sido importantes. Si bien el acceso al sistema educativo no ha bastado para sanar las abismales brechas y desigualdades educativas en la región pues las cifras de deserción y abandono del sistema han suscitado discusiones y preguntas en las que en este trabajo no se profundizará, se ha de subrayar que la tendencia general de las familias está dirigida a buscar la educación formal de sus hijos -cuestión que se refleja en las cifras. En Ecuador (en el Anexo 2 se explica de modo resumido la organización del sistema educativo en Ecuador):

"La mayoría de padres y madres creen en la escuela y hacen esfuerzos por matricularlos. Así un 90 por ciento de los niños ecuatorianos acceden al segundo año de educación básica. Pero, a medida que avanza el tiempo ese número se desgrana. La deserción es muy alta. Así uno de cada tres niños no llega a completar los seis años de educación primaria. Uno de cada cinco niños abandonan la escuela en quinto de básica (cuarto grado) y tres de cada diez niños y niñas de séptimo de básica deserta de la escuela. El problema se agrava con los adolescentes: el 46,9\% están fuera del sistema educativo y sólo un $22 \%$ de los jóvenes culminan sus estudios secundarios. La exclusión es más aguda con los niños y niñas con necesidades educativas especiales donde apenas un $6.1 \%$ tiene algún tipo de asistencia. Lo mismo sucede con los niños y niñas menores de 5 años, que hasta agosto del 2002 sólo un 13\%5 eran atendidos por programas estatales dispersos" (Luna, 2006: 3).

Si bien -como se ha señalado- no se pueden establecer generalizaciones sobre la clase social de las familias, sí se puede señalar que la migración ha provocado un proceso de desclasamiento: los padres y madres entrevistados no solo que ocupan ciertos puestos en el mercado laboral español, sino que estos: (1) no se corresponden con la posición social de los padres en el país de origen, ni con su titulación, estudios, experiencias y conocimientos previos; (2) son ocupaciones fuertemente precarizadas (construcción, servicio doméstico y cuidados, agricultura, hostelería...) y poco valoradas por hallarse en los estratos inferiores de la estructura ocupacional ${ }^{9}$. Las mujeres y hombres ecuatorianos que han migrado a España forman parte de lo que se denomina la nueva clase trabajadora o el proletariado étnico.

De esta manera, el acceso al sistema escolar de los hijos adquiere nuevos significados. Por una parte, papás y mamás esperan que la educación de sus hijos les permita salir de la situación en la que se encuentran o de modo más concreto, del sector de empleo en el que se hallan sumergidos:

"Entonces yo digo: "mientras estemos yo y tu papá juntos y estemos vivos y podamos darles hasta donde podamos, pues tienen que aprovechar. Si ustedes no aprovechan, tarde o temprano andarán como nosotros buscando trabajo y todo lo demás. Pero ustedes porque no han querido aprovechar" (Cecilia).

9 Sin embargo, como señala Actis (2005) los datos de la EPA y otras investigaciones indican que el nivel de calificación académica de buena parte de estos hombres y mujeres es superior al del conjunto de la fuerza de trabajo autóctona.. 
Se trata, según la perspectiva de esta mujer, de "aprovechar" la ocasión, responder a las oportunidades que la migración ha abierto a la familia y que consiste, según su discurso, en dos asuntos: por una parte, se asocia la oportunidad de estudiar al esfuerzo y el trabajo que ellos y ellas han hecho:

"Enrique no ha pasado las circunstancias por las que uno ha pasado porque uno siempre ha pensado "si yo he pasado, él no tiene por qué pasar". He debido salir a trabajar desde muy pequeño, me he superado, he pasado del colegio, he pasado la universidad, todo y uno lo primero que piensa es en los hijos, que no pasen lo que uno ha pasado. Si pueden tener llegar a ser alguien por medio del esfuerzo de los padres es en lo único que uno piensa" (Jaime).

Los sentimientos con respecto a la propia migración suelen ser ambivalentes y en este trabajo no se entrará en mayores detalles al respecto. Por ahora interesa señalar que, por un lado, se habla de los beneficios que el cambio puede traer (mayores ingresos, separación de parejas maltratantes o relaciones domésticas violentas, etc.) y por otro lado, la migración es asumida como un camino difícil y sacrificado:

"A nosotros sí nos hizo fuerte el dejar a toda la familia, es un golpe psicológico fatal, pero como se dice vulgarmente, si se ha venido para acá es para algo, hay que dejarse de lamentaciones y todo eso, claro que se sufre, pero ya que se está aquí, hay que luchar" (Manuel).

Aquel sacrificio, el dejar el allí atrás, en tiempo y espacio, adquiere nuevos significados a través de la presencia de los hijos en el país de destino: el sacrificio familiar se proyecta en la participación de los niños, niñas y adolescentes en la institución educativa:

"Y eso siempre les digo a mis hijos, que hemos tenido que venir acá por darles eso y todo lo demás. Ojalá lo que una les dice ellos entiendan. Todavía son... piensan que la vida es chiste” (Jaime).

"Nosotros no estamos aquí por hacer dinero, sino que mi hija dice que quiere seguir la carrera de médico, tú sabes que allá es tan difícil, en nuestro país" (Carmen).

La participación de los hijos en el sistema educativo español se convierte, de este modo, en la justificación del proyecto migratorio familiar y en la puerta para participar en un espacio que se asume menos excluyente y más horizontal que aquellos de los que los padres y madres suelen formar parte. En un contexto migratorio, la escuela simboliza la puerta de entrada a la esfera nacional. Por lo dicho, la educación formal (Moscoso, 2008) de los hijos/as de migrantes representaría un logro para toda la familia pues supone la adquisición de saberes que no se pueden aprender en el hogar, pero tampoco en el país de origen. En este sentido, cuando se indaga algo más en los discursos de los padres y madres alrededor del sacrificio familiar en aras de la educación de sus hijos en España, se encuentran varias ideas.

En primer lugar, se asume que la migración representa una mejoría económica familiar que se traduce en la posibilidad de que los hijos/as asistan a la escuela:

"Como yo les digo a mis hijos "el bien es para ustedes, no para mí. A mí no me han podido dar esos mis padres porque hemos sido muchos hermanos y mis padres eran pobres y no podían tener todo lo que tienen ahora" (Cecilia).

De hecho, la inversión en la educación de los hijos a través de su acceso a una institución que se considera que representa un camino hacia el ascenso familiar, suele tener lugar tanto en España como en Ecuador: 
"Entonces le dije que en qué colegio querían estar. Porque yo les quería poner en un colegio privado porque tenía posibilidades para ponerles, pero mi hijo no quería” (Lucía).

Según cuentan algunos padres y madres, al estar sus hijos en Ecuador antes de la reagrupación, ya se invertía en una educación considerada de mejor calidad que la que recibían antes del viaje de sus padres pues señalan haber tenido la posibilidad de enviar a sus hijos a un colegio pagado, es decir, privado. Incluso resulta interesante hallar casos como el de esta familia que ha ido y regresado varias veces. La capacidad de invertir en los estudios de los críos tanto en España como en Ecuador y el hecho de tener varias experiencias para comparar, conduce a valorar las ventajas y desventajas en uno y otro lugar - como la seguridad y los servicios que un colegio pagado puede ofrecer:

"Sí y este año estamos retomando la rutina de estudio de ellos, como estaban en Ecuador estuvieron controlados de otra manera porque allá van a un colegio pagado, religioso y el bus iba a dejarles y a recogerles todos los días que era mejor todavía porque así no tenían excusa de quedarse por ahí con los amigos o venir caminando" (Jaime).

En un caso u otro y sea cual sea la estrategia familiar en relación a la educación de los hijos, el hecho es que en los discursos, la migración de los padres se convierte en un sacrificio cuya recompensa debería ser encontrada en el éxito académico de los hijos. Ahora bien, existe la idea de que la responsabilidad del éxito escolar descansa en las niñas/as y jóvenes como alumnos y alumnas y en el esfuerzo que hagan:

"Le digo "lo que te guste, lo importante es que tú tienes que dedicarte, dedicarte y estudiar para que saques una buena carrera y tengas un buen trabajo, que estés tranquilito, no como nosotros que ya ves cómo nos toca, cómo nos ha tocado, todo por tí, eso tienes que valorar". Dice "sí mamá"(Carmen).

"Le digo "tienes que estudiar, poner de parte" (Lucía).

La dedicación y el estudio se suponen claves para un resultado feliz en los estudios lo cual, desde la percepción de los padres y madres, actuaría como una palanca que les permitiría saltar hacia otra posición social distinta a la de ellos. Sin embargo, según los datos existentes (García Fernández y Moreno Herrero, 2002; Franzé et.al; 2007), existe una abrupta caída del número de estudiantes hijos de inmigrantes, no solo en los niveles post-obligatorios, sino además entre el primer y segundo ciclo de la ESO, lo cual pone en duda que su trayectoria sea el resultado únicamente del esfuerzo que ellos y ellas pongan en sus estudios. Sin embargo, en el discurso de papás y mamás, el éxito académico de sus hijos está depositado casi de modo único en sus manos y en el esfuerzo que ponen o dejan de poner en los estudios. Así, el sacrificio familiar se convierte en un mandato: el éxito escolar. Lo contrario, es decir, la deserción o la repetición de años, representa un incumplimiento, no solo con el mandato parental, sino incluso familiar. En efecto, no sólo es papá y mamá quien aconseja, también lo suele hacer la familia ampliada, ellos forman parte del veredicto:

"Cuando llamo a Ecuador, mi familia, todos le aconsejan que tiene que aprovechar, que por él nos estamos nosotros sacrificando, para darle una buena educación. Entonces yo le digo que "vos no te vas a quedar sólo de bachiller, tienes que sacar una carrera, luego ya entras a la universidad", "sí mamá, yo voy a ser ingeniero como mi tío" porque tiene un tío que es ingeniero" (Laura).

Por otra parte, se percibe que el sistema educativo en España es mejor que el ecuatoriano porque es "más avanzado": 
"Entonces ahora como están ahí, yo creo que, como dicen mis hijos, es diferente el colegio aquí, es mucho más avanzado, dan materias más avanzadas, o sea, más adelantadas en ciencia y eso" (Laura).

El hecho de ser "más avanzado" también se traduce en la idea de que hay más medios (ordenadores, internet, bibliotecas, etc.) o espacios como el descrito a continuación:

“Anda por ahí, aquí hay un centro de estudios, ahora está allí en el ordenador. Es gratis, si tú quieres te inscribes y ya. Por eso te digo que hay ventajas, o sea, aquí hay más medios. Si esos medios hubiesen en nuestro país porque deben haber de sobra, con los presupuestos del gobierno, pero no lo hacen" (Jaime).

También circula la percepción de que los títulos obtenidos en España tienen más valor que los ecuatorianos los cuales no solamente que suelen ser devaluados en el mercado, sino que además, son difíciles de convalidar o reconocer. Papás y mamás valoran los títulos españoles sobre los ecuatorianos pues dicen que "valen más" tanto aquí como allá. Además, se cree que un grado obtenido en España supondría un salto social en cuanto a la posibilidad de ubicarse en otro lugar que no sea el que ellos ocupan:

“Aquí tienen que seguir un....¿cómo se dice?.....convalidar...tienen que hacer eso, estudiar uno o dos años y sacar el título. Pero de allá no sirve nada aquí. De allá la gente dice "yo soy esto, asado y cocinado"...pero aquí...están fregando el suelo, están limpiando. De allá no son nada porque mientras no traigan, tienen que hacer eso y todo lo demás. Oigo decir que aquí el colegio es mejor que allá, más avanzado" (Laura).

Resulta por lo menos curioso que las percepciones de los padres no consideren la exclusión a la que sus hijos podrían verse sometidos por su origen. De hecho, al preguntar sobre este punto, casi la mayoría piensa que sus hijos e hijas reciben el mismo trato que sus compañeros nacionales:

"Creo que a todos les tratan igual digo yo porque a todos les tratan igual...no, a todos igual" (Cecilia).

"En los colegios no hay, por ejemplo, no hay mucha diferencia en el sentido de trato. Están todos por igual" (Paúl).

De hecho, padres y madres se refieren a la incorporación de sus hijos a la escuela en términos de una "adaptación". Existe la percepción de que la experiencia escolar de los chicos y chicas ha sido exitosa en la medida en la que los padres y madres sienten que sus hijos han sabido ajustarse al nuevo espacio, sus ritmos y particularidades:

"Ellos aquí se adaptaron. No, de entrar entraron bien" (Jaime).

"Se adaptó muy rápidamente y yo me fui a traerle y a dejarle solamente una semana, quince días. Luego ya venía sola, comía en casa y se volvía a ir porque eran dos jornadas, entraban a las 9 , salían a las 12 y 30 , luego entraban a las 2 y salían a las 4 " (Cecilia)

"Y cuando vinieron, me asombré, se adaptaron rapidísimo, o sea, ni la comida les ha hecho bien, como si ellos hubieran ido de vacaciones y estuvieran volviendo para acá" (Paúl).

Sin embargo, al indagar algo más en su percepción sobre el sistema de enseñanza español, surgen las preocupaciones alrededor del papel de los profesores: 


\begin{abstract}
"Bueno, a mí me parece que aquí no les obligan mucho. En Ecuador están pendientes de los niños, yo siempre les he dicho a los profesores “¿qué pasa que los niños no llevan los deberes?” y los profesores siempre dicen "no, los niños están bien". En cambio en Ecuador les exigen, les mandan, es diferente la enseñanza. Mira, aquí lo que les mandan a los niños, yo veo, son redacciones y ellos se ponen..., en cambio, allá no. Allá les mandan deberes, ellos tienen que estar pendientes y todo. Esa es la diferencia. Yo tengo una amiga que dice que su niña tienen muchas dificultades en las redacciones, ese es el problema" (Carmen).
\end{abstract}

"En Ecuador le mandaban muchos deberes y aquí no. Igual a veces lo hacen en el cole, a veces lo traen a casa. Dicen "mami no te preocupes, ya los hice en el cole". En Ecuador no, llegaban, comían y se quedaban hasta las 8, 9 haciendo deberes" (Lucía).

La preocupación principal de papás y mamás tiene que ver con la noción de obligación la cual se relaciona al cúmulo de tareas que llevan a casa. Se mide la eficacia o el aprendizaje de acuerdo a la cantidad de deberes que llevan a casa, lo contrario es interpretado como una señal de poca exigencia y despreocupación. En Ecuador el sistema público de enseñanza suele caracterizarse por ser memorístico y poco pedagógico ${ }^{10}$, pero es el sistema que padres y madres reconocen y en el que han sido formados.

"Por ejemplo, las tablas aquí nada, hasta el 10 te dicen. Y los estudios en el cole, ellos no tienen que venir, allá te mandan a memorizar, que te aprendas las tablas, que te aprendas. Así mismo la cuestión de los exámenes, ellos vienen entrenados para que le den un repaso y vayan porque mi hija dice "ya tengo examen mamá" y yo le digo "ponte a estudiar" y ella dice "no, si ya sabemos" y los profesores están pendientes de ellos en esa cuestión de exámenes. Están revisando los temarios, esa parte es diferente" (Carmen).

Los padres se muestran extrañados e incluso cuestionan la idea de que a chicos y chicas se les permita desarrollar sus estudios según su propia iniciativa, "a la voluntad de ellos":

"Bueno, no lo sé, sería regular, no se cómo, pero cómo le digo. No sé cómo decir, es que allá les obligan a que estudien, aquí en cambio les dejan a la voluntad de ellos. Si quieren hacer lo hacen y si no, no. Allá los profesores les obligaban: "tienes que hacer esto o lo otro, sino te castigo", pero lo hacían. Aquí, yo he visto que mi hijo no lo hace. Le dicen que haga los problemas, el coge el libro, se queda allí sentado y no lo hace” (Lucía).

Como señala Lucía, la falta de presión por parte de profesores se traduce en un mayor trabajo para ella. Considera que el desinterés del profesor es un incumplimiento de su rol:

"Hay falta de interés, les deberían obligar a que hagan, que estudien. Falta de obligación de los profesores porque yo atrás de él estoy todos los días, con los deberes, que la letra, que la lectura... ahí sí me saca de las casillas" (Lucía).

Esto es interesante en la medida en la que denota la idea de que la mayor responsabilidad del cumplimiento y el seguimiento en el aprendizaje de los chicos y chicas es un asunto que descansa mayormente en la institución y en los profesores.

10 Más allá de los críticos, un logro importante de mediados de los noventa en Ecuador fue el impulso de la Reforma Curricular Consensuada. Sin embargo, por diversas razones, tal iniciativa, con el pasar de los años quedó en el papel, por lo que, en gran parte del sistema público, persistieron y persisten los viejos esquemas pedagógicos, programas académicos, textos y material didáctico poco pertinentes y desactualizados. Pervive el memorismo, los esquemas jerárquicos en las relaciones maestro-alumno y el maltrato (Luna, 2006).. 
Por lo señalado, se puede señalar que la representación que se tiene de los profesores se relaciona al esquema jerárquico maestro-alumno. Como comenta Cecilia, los profesores de sus hijos en Ecuador eran "buenos", otros "malos" porque les pegaban, pero en general, se refiere a una figura de autoridad casi paternal a la que se debe temer y respetar:

"Pues donde yo estaba eran buenos, enseñaban muchas cosas a todo el mundo. De allí de mis hijos pues ellos igual me contaban que eran buenos profesores, que hacían su trabajo de educarles. Siempre me han comentado mis hijos que "la señorita tal, que el licenciado tal", que eran buenos, pero claro, hay algunos que eran malos, que les pegaban cuando no les hacían caso. De todo nos comentaban, pero yo creo que los profesores sí son buenos, cualificados y hacen su trabajo. No puedo decir que sean malos" (Cecilia).

Lo señalado es importante en la medida en la que esta visión sobre los profesores les confiere una legitimidad que muchas veces se ha puesto en duda en el medio español. En general, los padres y madres ecuatorianos no sólo que demandan más atención y presión por parte de maestros y maestras, sino que además, tienen en general una visión bastante positiva de los mismos:

“(...) son guays, bueno, la profesora que la niña tenía era muy maja, se llamaba Charo, la quería mucho a mi hija porque decía que mi hija era muy educada, que llevaba las tareas, nunca tuvo problemas ella. Con los profesores mis hijos nunca han tenido problemas, ni me han llamado para decirme que no han llevado los deberes, que no han ido a clase" (Lucía).

Se confiere autoridad y legitimidad a la figura del profesor al que se le debe respeto y obediencia. El comportamiento ideal esperado por los padres se ajusta a los requerimientos de la institución escolar: sus hijos deben hacer las tareas, ser disciplinados, no dar problemas, ir a clase, en suma, como señalan los padres, los chicos y chicas deben ser "bien educados". Y la idea de "bien educados" es algo que, como señala esta mamá, se ha traído de allí pues se ha aprendido en casa:

"Tú sabes que la educación viene del hogar, no viene del colegio, sino del hogar” (Lucía).

El ser "bien educados" tiene significados que se traducen en una serie de códigos y normas de conducta que se deben guardar, en general, hacia todos los adultos, como por ejemplo, el uso respetuoso del usted y no del tú, el uso de un tono bajo de voz, obediencia, quietud, la prohibición de contestar o contra-argumentar e incluso, el silencio como signo de consideración ${ }^{11}$.

Por ejemplificar, a continuación Carmen explica cómo es allá, las diferencias, el hecho de que se habla de otro modo lo cual se observa en las formas de hablar, nombrar y decir las cosas:

"Pero como es diferente la educación allá y aquí, a veces no se entendía lo que decían aquí. Porque allá como se habla de otra forma o algunas palabras son las mismas, pero de diferente manera" (Carmen).

Lo anterior es significativo en la medida en la que sugiere que a la hora de entender la actitud de padres y madres de familia frente a la escuela, se han de tomar en cuenta cuestiones directamente relacionadas con las pautas de socialización y cuidado aprendidas en la sociedad de origen de las familias migrantes. Estas pautas de socialización se inscriben y están relacionadas con un sistema educativo fracturado por profundas brechas. El problema, en Ecuador, desde mi

11 Estos ejemplos constituyen una generalización. Es posible que entre la población afroecuatoriana, en ciertas zonas rurales de la costa o entre grupos indígenas de la Amazonía o la costa, exista una variación de estas normas. Así mismo, existen diferencias por clases sociales e incluso de género. Hasta donde conocemos, no existen estudios al respecto. 
punto de vista, no es el acceso a la educación, sino la división entre los colegios de élite/privados y los públicos y en el interior de unos y otros, entre aquellos que son de mejor calidad y los que no. Estas desigualdades suelen ser concomitantes a las de origen de los estudiantes:

"Si bien la región ha registrado importantes avances de una generación a otra en cuanto a años promedios de educación, esta tendencia al incremento de cobertura educativa coexiste con una alta estratificación de la educación: los logros educativos varían con el nivel de ingresos, la clase social, la ubicación geográfica (urbano-rural), lo que está perpetuando las desigualdades. (...) La equidad es sin duda el mayor desafío pendiente ya que persisten enormes brechas entre países latinoamericanos y estratos sociales en cada país, tanto a nivel de la provisión, participación, conclusión de los ciclos educativos y logros académicos. En este contexto la educación opera más como reproductora de la estructura social existente que como mecanismo para construir sociedades más equitativas. Por lo tanto, el mayor reto para los sistemas educativos es contribuir a construir una sociedad más justa" (Esteves, 2008: 17-18).

Como se señala, hay una brecha entre las instituciones de las zonas rurales y las urbanas y toda una gama de factores que diferencia a unas de otras de tal modo que no se puede señalar que no existan escuelas e institutos de calidad, sino que estos son inasequibles para la gran mayoría lo cual suele coincidir con el volumen de los capitales escolares de los progenitores lo cual, a su vez, suele reproducir círculos de pobreza:

"Nosotros también hemos estudiado allí yo mismo he estudiado allí y dependiendo de lo que se quiera estudiar. Nosotros no hemos sido nadie porque nuestros padres han tenido muchos hijos y no les han podido dar los estudios a nadie prácticamente. Sólo poner allí en la escuela, en la primaria que decimos, entonces ya no ha habido para eso y nosotros no queremos eso para nuestros hijos. Nosotros queremos que nuestros hijos sean alguien en la vida, por el futuro de ellos mismo" (Manuel).

Sin embargo, nos tememos que, según algunos estudios (Franzé, 2002; Poveda, 2003; Gabinete de Estudios FREM CCOO, 2005; Poveda et. al, 2007), ésta clasificación no sólo que no desaparece en el nuevo contexto, sino que más bien tiende a reproducirse. La escuela es un lugar en el cual se depositan una serie de valores y expectativas que no siempre se cotejan con las cifras y las realidades. Tanto en Ecuador como en España ${ }^{12}$ la tasa de deserción, los fracasos escolares y la segregación entre alumnos y alumnas en razón de género, clase social y etnicidad/ origen ponen en duda la idea de una escuela homogénea y que realmente brinda las mismas oportunidades a todos y todas. Sin embargo, al parecer, esta generación de padres y madres de familia cuyos hijos participan por vez primera en el sistema educativo español, aún no ha experimentado de modo directo el "fracaso" de sus hijos y estos aún no tienen otros hijos en quien proyectar, a su vez, sus propias ideas y prácticas sobre la educación y aquello es importante a la hora de entender las actitudes frente a la escuela.

Por tanto, si el mandato parental-familiar "que no sean como nosotros" corre el riesgo de no ser obedecido, surge una serie de preguntas e inquietudes sobre el peso que este incumplimiento tiene a nivel personal, familiar y social. Por un lado, habría que cuestionarse por qué motivo los padres y madres colocan la responsabilidad del éxito escolar en las manos de sus hijos e hijas, por qué, por una parte, la escuela tiene el peso que le confieren y cómo, por otro, se le resta responsabilidad en cuanto al rendimiento de sus hijos. Nos preguntamos, por ejemplo, si esta visión sobre los profesores/as como figuras de autoridad casi incuestionables, el peso otorgado a la educación y al papel de la escuela como palanca para el ascenso familiar no debería

12 Por ejemplo, en España en 2007 el fracaso escolar de un joven de clases agrarias (agricultores y jornaleros) es casi del séxtuple del de un joven de clase alta (31,4\% vs 5,8\%) (Martínez, 2007: 47). 
acompañarse de un discurso más exigente y en el caso de no ser así, por qué. ¿Existe acaso la percepción de que el acceso al sistema educativo es un favor y no un derecho?, ¿la ausencia de responsabilidades no tiene una función: reproducir un sistema atravesado por desigualdades a nivel local, regional y global?

Si bien la escuela sí hace la diferencia, no basta con acceder a ella. Las desigualdades económicas, sociales, nacionales/étnicas se reproducen a varios niveles y en distintas esferas que sobrepasan lo educativo, allí como aquí. Los destinos no se escriben únicamente en las instituciones a las que se ha tenido la oportunidad de acudir pues existen una serie de factores que inciden directamente en la vida de las personas y que marcan límites y fronteras. Así, otra cuestión que genera dudas es si en realidad, el "no sean como nosotros" tiene un significado únicamente económico y si en un contexto migratorio no entran en juego otros factores de exclusión como el étnico/nacional. ¿Realmente pasar por la escuela, significa dejar atrás la "condición migrante"?

En la tercera parte de este trabajo se presenta un análisis de los discursos de papás y mamás respecto a otros elementos para el análisis que estamos llevando a cabo. El objetivo es enfocar de modo más cercano los discursos sobre algunos de los factores que inciden en las trayectorias escolares de los niños/as y adolescentes de tal modo que sea posible conectar estas cuestiones con la visión que papás y mamás tienen sobre su papel en la educación de sus hijos.

\section{Percepciones sobre las trayectorias escolares}

Existen factores decisivos en las trayectorias escolares de los niños/as y jóvenes. A continuación se llevará a cabo un análisis de los discursos de papás y mamás alrededor de algunos de estos -el apoyo escolar, su participación en el espacio escolar, los criterios para la elección de la escuela y las expectativas familiares-.

En general, los progenitores señalan que en Ecuador, el criterio al elegir el centro educativo en el que sus hijos recibieron parte de su formación, corresponde básicamente a los siguientes factores: cercanía al barrio o pueblo, conocimiento previo de la institución -el haber asistido ellos mismos al ser niños/as/jóvenes- y el prestigio:

"Como nosotros vivimos en Pifo, siempre nos han dicho que es bueno porque no podemos decir "nuestra escuela ha sido siempre mala". La escuela donde les he puesto a mis hijos siempre ha sido buena, es famosa, es una escuela fiscal, no es particular, pero siempre ha sido buena. Todos mis hermanos han estudiado allí...yo no, yo no estudié allí. Entonces yo les he puesto allí a mis hijos y ha sido buena, sí y de ahí le puse en el colegio. Acabó la escuela, porque yo les dejé en la escuela y sabía que se iban de aquí al colegio y todo lo demás. No quería, decía que quería irse a otro colegio y les puse en el Nacional Tumbaco, allí han estudiado ambos hasta tercer curso hasta que les traje" (Lucía).

La escuela en la que Lucía ubicó a sus hijos en el país de origen es la misma a la que asistieron sus hermanos y además, como ella señala, a pesar de no ser privada, es "famosa". Este último criterio se conecta con lo expresado en líneas anteriores pues es común que en Ecuador se tome la exigencia y el autoritarismo como principios pedagógicos valorados por las familias. Esto es explicado por Venegas de la siguiente manera:

"Una tendencia natural, incorporada en el criterio común de la población, es el elemento de "prestigio», relacionado con la calidad de la educación. Este razonamiento puede tener un sentido utilitario en la educación, principalmente en una sociedad que ha construido ciertos imaginarios sociales de reconocimiento de la formación que reciben los estudiantes en determinado centro educativo. Inclusive muchas familias orientan su decisión de integrar a sus hijos en tal o cual establecimiento a partir del reconocimiento social que este tenga. El problema muchas veces 
es que esos criterios tienen algunos equívocos como criterio de calidad, uno de estos es que, en algunos de esos establecimientos, «son exigentes» lo que muchas veces significa autoritarios, poco participativos, sin mucha posibilidad de autoiniciativa o creatividad" (Venegas, 2007: 39).

En cualquier caso, la selección requiere de un elemento imprescindible: la información. En otras palabras, papás y mamás señalan haberse guiado por los conocimientos previos y por imaginarios alrededor del "prestigio" a la hora de elegir una institución y no otra. Estos conocimientos fueron adquiridos por medio de sus propias experiencias escolares, la de sus familiares y por el conocimiento público sobre la calidad de enseñanza de las instituciones. La pregunta que se desprende de lo anterior es, en consecuencia: ¿qué sucede con los conocimientos previos en un contexto nuevo?

Los discursos de los padres y madres sobre los criterios a la hora de ubicar a sus hijos en instituciones educativas en España permiten entender que estos conocimientos previos no son necesariamente compatibles con los requeridos:

"Yo cuando, o sea, yo ya sabia que les iba a traer a mis hijos, fui abajo un colegio. Yo nunca había utilizado eso. Me fui, pregunté y me dieron un papelito. Y me fui a preguntar por allá y me dijeron que no puedo hacer nada hasta que no estén mis hijos. Entonces cuando ya me dieron todos esos papeles, cuando llegaron mis hijos, ya me fui yo allá donde me mandaron. Ahí me ayudaron a buscar el colegio más cercano de casa y me fui acá y ya enseguida, al otro día ya estaban en el colegio" (Lucía).

Según las palabras de Lucía, tuvo que preguntar, anduvo por allí, se acercó a la institución más cercana, le dieron un papelito y así sucesivamente hasta lograr la entrada de sus hijos. Hoy en día éstos asisten al colegio más cercano de casa. Jaime, en cambio, comenta cómo hizo él también las gestiones para el ingreso de su hijo, pidió cupo y logró una plaza en el instituto que es más cercano a su casa y al que ha asistido previamente su hija menor:

"Por medio de la escolarización y porque estaba su hermana allí, la pequeña. Entonces fui a la escolarización y le dije que quería que me de un cupo, cómo dicen aquí, una plaza para el niño, me dijeron que si tenía hermanos, les dije que sí, que tenía una hermana que estaba en el colegio y que quería que me den ese mismo colegio para él porque me queda cerca de la casa y me lo dieron. Me lo dieron enseguida" (Jaime).

Como se observa, según se desprende de los discursos, el criterio se ajusta básicamente a las distancias impuestas por su trabajo, la cercanía entre este y el instituto o con la casa:

"Mi hijo vino de 5 añitos, le busqué plaza en un cole que me acuerdo queda por el metro Ibiza. Yo le llevaba antes de ir al trabajo, me iba a trabajar y lo retiraba y lo tenía hasta que me toque la hora de salir a la casa. Y bueno, ahí estuvo hasta que terminó el año, poco estuvo. Luego me tocó cambiarle porque era muy lejos. Más que todo me quedé sin trabajo porque la señora para la que trabajaba falleció, entonces me tocó buscar otro trabajo y me tocó cambiarle a mi hijo de colegio cerca de aquí, donde vivo, en la calle Rosales. Allí ha terminado la primaria y luego pues ahora ya está en el este instituto" (Laura).

Ningún progenitor se refiere al prestigio de las instituciones para ubicar a sus hijos. La gran mayoría señala haberse guiado por la cercanía a sus hogares o sitios de trabajo. Sin embargo, de los discursos se extrae que a pesar de las pocas posibilidades de elegir, los padres migrantes también elaboran estrategias que permiten cubrir el poco conocimiento del medio:

"No, de entrar entraron bien porque mi mujer trabajaba para una profesora de ellos, entonces por ahí hubo la facilidad que hubo, entonces llegaron y al segundo día ya estuvieron yendo al cole" (Jaime). 
Las $\operatorname{redes}^{13}$ tienen un valor fundamental para sostener, reproducir e intercambiar bienes simbólicos y materiales. Estas poseen un papel tanto a la hora de elaborar contactos como en la transmisión de información. El apoyo de las redes ${ }^{14}$ puede convertirse, por lo señalado, en una estrategia a la hora de elegir una institución u otra. En el caso anterior, por ejemplo, la esposa de Jaime se ayudó de la influencia de su contratante para obtener un cupo en el instituto y en el que sigue, es el amigo del marido quien le "recomendó" una institución:

"Cuando vine, mi marido tenía un amigo que le dio la carta para que vengamos. Entonces tenía su hijo allí en el instituto. Y me lo recomendó y entonces yo fui y me los aceptaron y ellos no tuvieron problema porque venían de una buena escuela de Guayaquil" (Carmen).

Como se ve, si los criterios para la selección de la escuela en el país de origen han sido la proximidad física, el haber estudiado allí o el prestigio de la institución, se entiende que en España estos criterios se juntan con otros, chocan, permanecen o se transforman. En este sentido, el papel de las redes es fundamental pues no sólo que pueden servir como un espacio para establecer contactos, sino que además, brindan información sobre las instituciones, su funcionamiento e incluso sobre los requisitos burocráticos que se debe cumplir.

El criterio pedagógico (prestigio) desaparece de los discursos y vuelve a aparecer una vez que los chicos ya forman parte de la institución. Por otra parte, llama la atención que en los discursos no se aprecie algo que es fundamental y que sin embargo, padres y madres parecen desconocer a la hora de elegir un lugar de enseñanza u otro: la clasificación de los alumnos, la separación entre unos estudiantes y otros por su origen o clase social, la excesiva concentración de las minorías en unos centros y ausencia en otros, la presencia o falta de medios materiales y humanos para atender a las necesidades específicas de sus hijos en las aulas, etc.

Otro punto a considerar es el apoyo escolar y las ideas que subyacen a las prácticas. Para los progenitores, este se relaciona con la ayuda y con el seguimiento personal. La ayuda puede hacer referencia al acompañamiento o seguimiento, al refuerzo en la preparación de los exámenes y el estudio, en la profundización de lo que se ha aprendido en clase o la realización de las tareas.

Generalmente, esta ayuda depende del capital escolar de los padres y madres, del tiempo del que disponen para dicha actividad e incluso de la organización familiar. En efecto, como se observa a continuación, el apoyo escolar no es una actividad en la que han participado únicamente papá o mamá, sino también hermanos mayores o miembros de la familia ampliada. Carmen, por ejemplo, es una de las pocas madres de familia que señala tener más tiempo en España que en Ecuador. Este tiempo se dedica a estar "pendiente de sus tareas y obligándoles a hacer las cosas":

"Yo aquí más porque como estoy con ellos como en Ecuador no pasaba con ellos, mis hermanos se encargaban de revisarles los deberes. Yo no, llegaba tarde, cansada, luego a cocinar, a comer, uh, a preparar para bañarles. Casi no he estado atrás de ellos, aquí sí porque como trabajo tres horas en la mañana y el martes y jueves vengo más tarde, pero siempre estoy con ellos, pendiente de las tareas. Siempre estoy obligándoles que tienen que hacer bien las cosas" (Carmen).

13 Entendemos por cadena migratoria a la transferencia de información y apoyos materiales que familiares, amigos o paisanos ofrecen a los potenciales migrantes para decidir, o eventualmente, concretar su viaje (...).Las cadenas forman parte de una estructura mayor: las redes migratorias, las cuales son más extendidas y están relativamente afianzadas, desarrollan una dinámica propia, que incluso puede desprenderse de los estímulos y desestímulos de la sociedad de destino (Pedone, 2005: 109).

14 García Borrego (2008) distingue cuatro tipo de formas en las que las familias se vinculan con las redes: (1) familias más asentadas aisladas de redes; (2). familias más asentadas conectadas a una red; (3). familias menos asentadas aisladas de redes; (4) familias menos asentadas conectadas a una red. 
Carmen señala que en Ecuador, al no haber dispuesto de tiempo, eran sus hermanos quienes se encargaban de hacer el seguimiento en el cumplimiento de las tareas. Se deduce que este tipo de apoyo, la atención y los refuerzos en las tareas escolares no es sólo competencia de papás y mamás, al contrario, como ellos señalan, en Ecuador muchas veces se recurría a familiares o hermanos mayores:

"Pero siempre tengo que estar atrás de él, pero la hermana es la que le ayuda más, que no sabe y le suele estar diciendo que le ayude" (Cecilia)

El apoyo escolar ha sido, en suma, una actividad en la que han participado varios miembros de la familia, algunas veces por una cuestión de tiempo -el abuelo- y en otros, por poseer un mayor capital escolar -la sobrina universitaria:

"El que se ocupaba pues, mi padre o mi sobrina, una sobrina que justamente ese tiempo estaba en la universidad, le ayudaba. Pero le costaba. Lloraba, que no quería hacer, que tenía sueño y tantas cosas" (Laura).

En el contexto español, al contrario de lo que suelen señalar comúnmente las profesoras/ os -que manifiestan el poco interés de los padres y madres migrantes en la educación de sus hijos- la mayoría de progenitores señalan llevar a cabo un seguimiento que se mide en la presión que dicen poner en casa a través de reglas (control del tiempo frente al televisor, al juego y estudio), en la atención sobre aspectos formales de las tareas (la "buena" letra, la ortografía y gramática), en la observación del cumplimiento de las tareas o en el conocimiento de las notas y los resultados:

"Que haga buena letra, que haga bien las tablas porque siempre se falla, en ortografía igual o bien se come las palabras o no pone mayúsculas o no pone en las palabras que tienen mayúsculas" (Carmen).

"No, tengo una libreta y tengo que firmarla, así los controlo. Los exámenes de los niños los mandan para que sus madres lo firmen" (Lucía).

Otros, en cambio, confían en los recursos que el medio ofrece a sus hijos (materiales pedagógicos, textos escolares, internet) como un suplemento a lo que ellos consideran ya no poder llevar a cabo:

"Muy poco le ayudo porque tienen muchas cosas aquí para, no creas que es como allá, aquí te piden mucho más, casi tienen todo ellos mismo, tienen los cuadernos, los libros. Sacan mucho de internet, es una de las herramientas más ágiles para estudiar, entonces hacen allí la mayoría de las consultas. Yo si te digo la verdad para ayudarles muy poco, muy poco les puedo ayudar, ya casi no me acuerdo" (Jaime).

Aquellos que señalan no ayudar directamente en las tareas lo justifican por medio de varios argumentos -falta de tiempo, dificultades en la comprensión del lenguaje o los contenidos- :

"No, yo no le ayudaba. Ella hacía sola, bueno, algunas cosas que le decían, me preguntaba. Pero como es diferente la educación allá y aquí, a veces no se entendía lo que decían aquí. Porque allá como se habla de otra forma o algunas palabras son las mismas, pero de diferente manera. Entonces yo no sabía cómo "no se mija, no sé, esperémosle a tu papi que venga para que él nos explique" (Carmen).

Carmen explica que la educación es diferente allá y aquí lo cual radica, según ella, en los modos de hablar distintos lo cual constituye una barrera para ella misma como mamá pues 
señala no haber entendido lo que se solicitaba a su hija. Jaime, por ejemplo, dice que en Ecuador sí le era posible apoyar a sus hijos, pero que en España los contenidos son muy diferentes:

"Hay diferencias porque date cuenta que en historia te enseñan la historia de aquí, no la de allá. Muchas cosas, por ejemplo, el inglés, hay materias que allá no hay y aquí sí. En eso tienen un poco de problemas porque se atrasan dos años y cuando van de aquí, allí tienen otras materias. $\underline{\text { Por }}$ ejemplo, aquí enseñan geografía de España, cuando vas a Ecuador tienes que estudiar la geografia de Ecuador, entonces hay materias que se cambian de nombre. No se el nombre de las materias, pero materias que tienen un nombre diferente a pesar de que es lo mismo. Eso es" (Jaime).

Esto significa que existen casos en los que a los padres y madres les resulta complicado ayudar a sus hijos en las tareas debido a sus propias dificultades para entender ciertos términos o al contenido disímil de las materias. Por otro lado, la carga de trabajo tampoco les permite pasar tiempo en casa lo cual se refleja en el tipo y la calidad del apoyo escolar que brindan a sus hijos:

"Mi jornada completa es partida, voy trabajo y al mediodía voy a la casa y como y luego toca volverme. 4 y 30 tengo que recoger unos niños del cole, llevarle a su casa, de 4 y 30 a 9 y así es de lunes a viernes. El sábado trabajo donde un periodista, ya llevo donde este señor 7 años trabajando y me toca 5 horas. Allí al menos me ayuda mi marido para terminar más pronto, el sábado a primera hora debemos hacer la compra, preparar la comida, comemos y enseguida toca ir y venimos a las 9 o 9 y 30. Sólo tengo así un domingo, nada más" (Cecilia).

"Luego mi marido, es él quien llega primero, el que le controla, tienen una agenda en la que anotan todo y pues él le controla porque le digo que yo llego a casa 9 y 40 , él está llegando a las 8 , él es el que le controla" (Laura).

Otra madre, en cambio, refleja otra estrategia de apoyo basada en el uso de material de apoyo (una enciclopedia):

"No, yo no puedo, yo estoy aquí para lo que necesite, tenemos una colección, nos ponemos a verla y también va al instituto los martes y jueves para que le ayuden. Aquí es diferente, ya tú sabes" (Carmen)

En realidad, la idea de ayuda a veces parece no reflejar el tipo de apoyo que dicha actividad representa pues en el caso anterior, por ejemplo, se percibe que las madres pueden llegar a recurrir a materiales extraescolares con el objeto de favorecer el aprendizaje de los chicos/as. Así, una mayoría de padres y madres llevan a cabo una revisión o seguimiento del cumplimiento de las tareas que muchas veces se describe como una ayuda que invisibiliza el trabajo:

"Yo no le ayudo, pero le reviso" (Lucía)

Otro elemento tiene que ver con lo señalado en líneas anteriores: al parecer algunos padres no se implican demasiado en la escolaridad de sus hijos pues mantienen una actitud de respeto hacia los enseñantes. El tipo de apoyo no siempre es el que la escuela demanda, se ayuda y se apoya sí, pero sin romper los límites con lo que el maestro o la maestra enseña.

Sin embargo, al contrario de ciertas ideas que circulan con facilidad, esto no quiere decir que los niños/as y jóvenes hijos de migrantes no reciben un sostenimiento familiar. Como se puede ver a continuación, muchas veces se recurre a las estrategias que ya se implementaban en Ecuador, es decir, a la búsqueda de ayuda en otros miembros de la familia con mayor tiempo y/o capital escolar: 
"Pero como ya me ve que no le obedece ni a ella, ella le dice "haz lo que te de la gana, no quiero saber nada, no me importa que te peguen" (risas). Así le dice, yo le digo "tú no eres la defensora del vago" y ella dice "no, ya no quiero porque ya no me obedece, ya no quiero ser la defensora". Es que es ella, la hermana la que le ayuda con los deberes." (Cecilia).

Como se observa, la hermana mayor - quien a su vez llegó con 8 años a España y hoy tiene 15- asume varios roles: no solamente que apoya a su hermano en las tareas escolares, sino que además, asume un rol maternal ${ }^{15}$ a pesar de no haber concluido el instituto.

David, según cuenta su madre, no sólo que en Ecuador estaba acostumbrado a recibir apoyo por parte del tío que iba a la universidad, sino que incluso, en el contexto español, tras varios intentos fructuosos, la familia termina por utilizar las estrategias a las que solían recurrir antes de migrar:

“Tuvo dificultades más en matemáticas y como allá mi hermano mayor es licenciado en física y matemáticas, me acuerdo que aproveché que viajaron con mi esposo y mi hijo a Ecuador y aproveché que ese mes que estuvo que le explique y haga entender lo que mi hijo no entendía aquí. Aunque mi marido siempre está pendiente, llega primero, le está revisando los deberes, las tareas que debe hacer. Pues nada, por más que le enseñaba, le indicaba, pues nada y mi hermano en un mes le puso al tanto y le ha servido bastante. Es pues diferente, es pues diferente, así por un lado, le ha hecho entender muchísimo a mi hijo, le ha valido bastantísimo ahora que está en el instituto. Como le tocó repetir pues también ya mejoró sus notas, ya entendió mejor. Por ese lado, ha tenido problemas, de ahí las otras materias, bien, bien le ha ido. Yo me acuerdo que estuvo malo y le cuento que repitió, le anoté en eso de planeta que le daban clases por teléfono a mi hijo, yo pagaba una mensualidad y él tenía que llamar y decir "mira, esto tengo ahora y no entiendo" y por teléfono había un profesor que le explicaba y le decía "mira, esto es así”, pero no funcionó" (Laura).

Finalmente y luego de insistir, la madre de David menciona el apoyo recibido en el instituto:

"Si, está recibiendo en el colegio ayuda. Va dos días a la semana y le está ayudando bastante y cuando estaba en el cole, yo pagaba una hora más para que a mi hijo pues en lo que sea le ayuden" (Laura).

David ha recibido varios tipos de apoyos: el familiar/redes el cual es el más valorado por Laura, el apoyo brindado por el colegio en la tarde -PROA- (del cual no se habla sino al final), el recurso de ayuda vía telefónica (que no dio resultados) y el control puntual que hace el padre. El hecho de que a los ojos de su madre, David haya mejorado su rendimiento en matemáticas gracias a las explicaciones de su tío en Ecuador, debería llevar a cuestionarnos sobre el tipo de apoyo que se oferta, los caminos para hacerlo y los requerimientos reales por parte de los hijos de inmigrantes.

A la sobrecarga de trabajo de papás y mamás (en especial el de las mujeres quienes no sólo que deben dedicar largas e intensas jornadas de trabajo al cuidado de niños y ancianos, a llevar a cabo tareas de limpieza a lo que se debe agregar el trabajo llevado a cabo en sus propios hogares -cocina, limpieza, aseo-cuidado hijos), se deben sumar otros factores que dificultan el aprendizaje de rutinas y hábitos de estudio: la falta de recursos y apoyos -no todos cuentan con libros, diccionarios, textos-, ausencia de un espacio para desarrollar las tareas, el impacto de la televisión y los videojuegos, etc.

15 Habría que distinguir las desigualdades de género que se reproducen en el hogar, el modo por el cual las chicas siguen asumiendo las tareas clásicas asignadas al espacio privado/hogar y las repercusiones en su propia trayectoria. Otro elemento importante en la organización familiar es el orden de nacimiento, la relación de edad entre unos y otros y los distintos recorridos escolares, es decir, la posición ocupada por los hermanos en la fratría. 
Ahora bien, en lo que respecta a la participación de los progenitores en la institución la cual también suele ser pasto de interpretaciones culturalistas (Franzé et al., 2007), esta es entendida en términos de las citas con los tutores cuyo objeto principal es conocer el rendimiento de sus hijos:

"Sí, siempre estoy preguntándoles. Recientemente me fui con él, cogí una cita y fui a hablar. A los 15 días otra vez fui porque me había mandado una nota que no participa en clase, que no hace nada, que no atiende, que está distraído jugando con los compañeros. Entonces le anoté en la agenda y le digo que me traiga la nota de la profesora para cuándo me ha dado la cita y me fui a hablar con ella" (Cecilia).

Generalmente, los profesores solicitan que los padres se acerquen a la institución en caso de existir algún "problema" con lo cual, papás y mamás relacionan su participación con los conflictos o dificultades de sus hijos. Un segundo motivo para acercarse a la escuela es el burocrático y la toma inicial de contacto con el medio:

"Yo me he acercado ese día que les fui a dejar a mis hijos. Me he acercado y allí le he conocido a la directora para hacerles matricular-como decimos nosotros- a mis hijos" (Lucía).

Así mismo, otro modo de relacionarse con el instituto representa la asistencia a las reuniones:
“A la primera reunión sí fui, estuve presente, pedí permiso en mi trabajo, pedí permiso y pues nos han dado un número de teléfono pues cualquier inquietud que tengamos, para que pidamos cita y podamos hablar con su tutora. Yo ya pedí, o sea, le dije que me de un día y no pude acercarme porque me dieron un día que no podía ir y le dije a mi hijo "dile esto a tu tutora que esto ha pasado y que otro día cuando pueda yo, voy a intentar acercarme y preguntarle cómo va y que lo que necesita estoy pendiente". Ellos tienen nuestro número de teléfono, si hay un atraso o algo, ya nos llaman por teléfono" (Lucía).

Sin embargo, la falta de tiempo vuelve a convertirse en un factor importante que dificulta la participación en las actividades convocadas por el instituto.

"No he participado en nada, pero cuando llaman a las reuniones sí me he ido. Pero participar en otras cosas, no he participado, no he tenido tiempo" (Laura).

Entre todos los entrevistados, apenas una madre ha asistido a la escuela para padres. Como ella señala, no regresó debido a las faltas y después, a la vergüenza de asistir a un espacio al que se asiste con cautela. Cecilia ${ }^{16}$ explica que el contenido de lo impartido le resultó interesante, pero que, una vez más, el tiempo le imposibilitó continuar con la actividad:

"Es para explicarles sobre la adolescencia de los hijos, a qué tiempo cambian, igual cómo ha sido la vida de ellos, cómo ha sido nuestra vida, nuestra niñez. Todo eso. Me gusto mucho. Sí quería asistir, pero ya no pude. Quería asistir a todas las clases hasta terminar pero ya no fue posible. La otra semana quise ir, pero tuve que salir para hacer otras cosas. Ahora con tres faltas digo "ya no voy" (risa), me da vergüenza" (Cecilia).

16 Aparece nuevamente la división de roles por género como un elemento fundamental en el análisis (el hecho de que sean las madres las que participan y se acercan al instituto, a modo de una prolongación del papel asignado de cuidado y crianza de los hijos) que merece ser tratado con mayor profundidad. 
En general, el tipo de participación de los progenitores se concreta en la asistencia eventual a las convocatorias de las instituciones o a través del control académico y disciplinar de los chicos por medio de encuentros esporádicos con los tutores. Al respecto se pueden señalar dos asuntos. Por una parte, la institución educativa no es precisamente un espacio abierto a la participación de todos y todas por igual y los niveles de implicación de padres y madres migrantes constituye más bien un reflejo de estas dinámicas. En segundo lugar, a lo mejor cabría preguntarse si cuestiones sutiles en el nivel informal (tales como el miedo a la sanción social y profesional) tienden a obstaculizar la participación de papás y mamas, o si el hecho de no compartir la cultura profesional, el origen y la clase de los otros con quienes deben interrelacionarse (autoridades, maestros, tutores, etc.) representa una frontera.

En cualquier caso, es interesante observar que existen distintas fronteras entre la escuela y las familias migrantes -simbólicas, lingüísticas, económicas, sociales, espaciales- y que una de ellas se refiere a lo señalado en líneas anteriores: el desconocimiento de la organización del sistema educativo. Como se verá a continuación, esto incide incluso en la elaboración de expectativas escolares de papás y mamás con respecto a sus hijos.

En efecto, de los discursos de los progenitores alrededor de las expectativas escolares se extrae que la falta de información también es un inconveniente común a la hora de tomar decisiones sobre el futuro de sus hijos:

"Me dice "mami, es que aquí no cojo profesión, no se qué voy a seguir, no se para qué estoy estudiando". Le digo "es que tú deberías haber preguntado en el colegio, tú estás yendo, debiste preguntar qué profesiones hay" y me dice "es que yo no lo sabía" y ahora quiere que le cambie de colegio. Dice que le busque porque dice que allí no hay la profesión que ella quiere coger" (Cecilia).

Las trayectorias escolares de los niños/as y jóvenes están influenciadas por las expectativas de papás y mamás, por aquello que se espera. Estas tienen un papel fundamental tanto en la formación de las expectativas de los propios niños/as y jóvenes como en las decisiones familiares que se toman o dejan de tomar en el camino. En este sentido, es importante entender que para algunos papás y mamás la organización del sistema escolar español no es similar al que conocían:

"Entonces nos dieron las matrículas, un formulario para nosotros desconocido porque era la primera
vez que estábamos haciendo, es súper diferente que por allá. Allá es más fácil, aquí era como
hacer una cosa por primera vez, estábamos confundidos, siempre preguntando como hay que hacer,
entonces nos resultó difícil, bueno no tan difícil, pero sí con cosas que no sabemos cómo hay que
hacer" (Manuel).

"Yo no sé, como yo no entiendo aquí nada de colegios...yo no le puedo decir eso. Tendría que preguntarles a mis hijos. De ahí del colegio yo no puedo decir nada porque yo nunca he tenido... primera vez que estoy haciendo esto" (Laura).

Si bien se debe hablar de una gama de conocimientos y herramientas escolares que tienen que ver directamente con los capitales escolares y culturales de los papás y mamás los cuales facilitan o dificultan el conocimiento del orden de las instituciones en un contexto migratorio, la organización escolar posee sus particularidades. Así, algunos progenitores no saben cómo se divide el instituto, cuántos años deben estudiar sus hijos, qué opciones existen o cuáles son los requisitos para continuar con los estudios. Este desconocimiento incide directamente en los discursos alrededor de las expectativas. Existe pues, una relación directa entre las opciones y las expectativas: menos información es igual a menos capacidad de elección (en caso de que exista la posibilidad de elegir). 
Ahora bien, la falta de información no representa de ninguna manera un obstáculo para elaborar expectativas acordes a la situación. De hecho, según los discursos de los progenitores, generalmente desean que sus hijos tengan un título, una carrera o una profesión:

"Al menos que mi hijo sepa que es alguien en la vida. Con eso me conformo, lo que sea, ¿ya?, pero que tenga un título y que sea alguien en la vida, con eso me conformo, yo no puedo decir que ni esto ni lo otro. Lo que esté en el destino, pero que él tenga una carrera" (Manuel).

Como se ha señalado al principio, la mayoría de los padres y madres expresan la necesidad de que sus hijos logren una formación que les permita alcanzar un status y posición social superior al suyo y el camino reconocido para alcanzar dicha meta es el académico. Ahora bien, el hecho de hacer una carrera o tener una profesión suele ser ambivalente pues puede significar varias cosas al mismo tiempo. Una madre, por ejemplo, relaciona el "coger una profesión" con el "ponerse a trabajar":

"Lo que yo digo es que ya en cuarto coja profesión, que sepa lo que va a seguir ella. Como ahora mismo no sabemos, no se en qué va a quedar. O sea, en 4to se coge la profesión allá. Ya dos años más y salen ya graduados. Aquí dicen que terminan el bachillerato, siguen la universidad, ni se qué, ni se cuánto" (Cecilia).

Las expectativas con respecto a la educación de su hija están cruzadas por lo que, desde su perspectiva suele ser una opción en el sistema educativo ecuatoriano: no cursar los últimos años requeridos para ingresar a la universidad, sino realizar, a partir de cuarto año, un ciclo de uno o dos años que habilitan al estudiante a aprender un oficio. Así, a los 14 o 15 años aproximadamente, chicos y chicas empiezan a trabajar al tiempo que dejan de estudiar y aquello se ajusta a lo que los padres esperan.

En Ecuador ${ }^{17}$, el ejercicio de estos oficios no representará una fuente de ingresos que permita transformar la situación familiar ni llevar a cabo un salto socioeconómico. Es más bien un modo de independizarse o apoyar a la economía familiar. Además, son pocas las familias dispuestas o que pueden permitirse mantener y pagar los estudios de los hijos mientras estos asisten a la universidad o concluyen el instituto - estando éstos en edad de producir.

Para Manuel y Lucía, por ejemplo, la posibilidad de que su hijo continúe los estudios secundarios representa un cambio con respecto a la situación personal de ambos (él en Ecuador era mecánico y ella doméstica y ambos estudiaron apenas seis años). Las opciones planteadas se dividen en dos: en Ecuador, se había pensado en que aprenda mecánica, al igual que su padre:

"No sé, pero yo en Ecuador le dije "ite pongo en un colegio de esos en los que se aprende mecánica?", le digo "porque tu papá dice que cuando eras chiquito... y que vas a ser mecánico" y dice "no, eso es muy sucio" (risas). Entonces dijo que eso era muy sucio y le dije "entonces dónde quieres estudiar" porque tampoco le iba a meter a la fuerza al colegio cuando él no quiere. Entonces dijo "yo ir al colegio ese", decía que quería seguir el físico-matemático ese que dan en Ecuador. Pero "esa carrera no se mijo. Tu verás" (Lucia).

17 Como señala Viteri (2007) según la CEPAL, en Ecuador el capital educativo mínimo, en términos de acceso al bienestar y al correspondiente ingreso laboral, demanda completar el ciclo secundario y cursar por lo menos 12 años de estudio. Cuando se ingresa al mercado laboral sin haber completado la secundaria, uno a tres años más de estudio no influyen mayormente en la remuneración percibida, y en la mayoría de los casos de poco sirven para salir de la pobreza. 
En el contexto español, la expectativa es otra: una carrera. Sin embargo, el padre se refiere a una "carrera rápida" con lo cual no se termina de salir del círculo al que hemos hecho referencia:

"Si, querría que estudie, que acabe de estudiar la escuela y siga lo que él quiera seguir, si quiere seguir una carrera más rápida, igual depende de ellos porque cuando estén mayores...pero que siga estudiando, que tenga una carrera para que se desenvuelva en la vida porque si no, si no quiere estudiar, ni tener una carrera, cómo va a desenvolverse" (Manuel).

Por otra parte, Jaime, dueño de un título y una trayectoria educativa distinta a Manuel y Lucía, espera que su hijo ingrese a la universidad y se forme en la misma carrera que él:

"El quiere seguir la misma carrera que yo he seguido. Entonces ha estado estudiando contabilidad ya" (Jaime).

Como se puede observar, las expectativas con respecto a la educación de los hijos tiene varios significados. Los discursos mezclan el deseo de que obtengan un título, carrera o estudios que les permita trabajar o mejorar la situación familiar con sus propias convenciones alrededor de lo que eso significa. Aquí, el peso de los habitus escolares de los progenitores es fundamental. Ahora, bien, los discursos sobre las expectativas escolares señalan un tercer camino: volver.

"Mi hija mayor no se enseña, dice "mami, mándame, mándame". Ella dice que..está en cuarto de ESO y dice "mami, pero si aquí no tengo ninguna profesión, estoy estudiando de gana y yo ya no quiero estudiar, quiero que me mandes a Ecuador". Allá en Ecuador se coge la profesión en cuarto. Le digo: "pero si cuánto me ha costado traerles para vuelta enviarles nuevamente, quedarme sola y preocupada por ellos, mejor espera un poco más y a ver si tomamos la solución de irnos todos". A pesar de que mi marido no quiere. El no quiere irse, le digo bueno que él se quede y nosotros nos vamos porque no podemos estar así" (Cecilia).

Si bien esta mujer valora la educación de sus hijos, repite lo que señala su hija mayor y de algún modo, incluso llega a apoyar el proyecto. Se percibe, además, una diferencia de perspectivas con el padre quien en cambio desea permanecer e incluso se llega a plantear el regreso sin él. Ahora bien, lo que las palabras de Cecilia no permiten descubrir es si es ella quien ha logrado implantar sus propios deseos en los de su hija o si es el deseo de la hija sobre la madre o si son ambos deseos que, motivados por razones distintas, calzan entre sí.

En el discurso de Cecilia la ecuación es la siguiente: su hija no tiene profesión -le quedan años de estudio-, en el país de origen se trabaja con menos edad, la hija no se acostumbra. En lo anotado, existe cierta confusión entre las prioridades de Lucía. Mientras otras señalan estar convencidas de tener que obligar a sus hijos a que terminen el instituto y continúen sus estudios, ella valora otros elementos que justificarían el hecho de que su hija no termine el instituto los cuales se relacionan con el ambiente en el que está creciendo, en la falta de libertad y espacios, en la ausencia de la familia ampliada:

"Porque dice que no, porque allá tienen más libertad...¿̨ómo le digo?..o sea, más campo libre digamos. Porque aquí es del colegio a la casa y de la casa al colegio, no sale a ningún sitio. A ella no le gusta salir ni nada, en cambio allá, tengo, tiene primos, primas, familia por parte de mi marido que vive a un lado, al otro. Entonces ella se va... Igual tengo una sobrina que es de la edad de ella misma y entonces se va con ella y tiene más libertad" (Cecilia).

La idea del regreso se asocia a dos cuestiones que se relacionan entre sí: por un lado, se señala que los chicos no se terminan de acostumbrar al medio en el que viven: 


\begin{abstract}
"Pero en realidad ya no quiere estar aquí, desde que el viajó a Ecuador hace dos años pues él ya vio allá como es, o sea, nuestra gente, otro ambiente. O sea, cuando él vino, vino de 5 años y cuando fue pues ya fue de casi 11 años, fue grande y todos emocionados de verle y todos sus primos fueron a verle, emocionados de verle a él, pues él se emocionó tanto y sintió el calor de la familia y él ya no quería volver, me acuerdo que por teléfono me decía "mamá, por favor, déjeme, yo ya no quiero volver a España”, “¡por qué?” le digo, "porque aquí en Ecuador es más bonito que en España"(Cecilia).
\end{abstract}

"Al comienzo no querían venir, luego querían venir. Ahora Erick quiere sacar el título aquí y luego quiere irse" (Laura)

"Tú sabes que la educación viene del hogar, no viene del colegio, sino del hogar, entonces sí, mis hijos están contentos, entonces sí, mis hijos están contentos, aunque cuando se gradúen se quieren ir de España porque no se enseñan" (Carmen)

En este artículo no se profundizará en el hecho de que, según papás y mamás, los hijos no se acostumbran del todo al medio español, pero sí se enfatiza la idea de que el momento de partir, tal como esta planteado, debería ocurrir luego de la culminación de los estudios (instituto).

Otro factor que cobra fundamento como argumento para volver es la actual crisis económica en España y el respectivo empobrecimiento de los sectores más frágiles de la economía, como el migrante:

"Eso hacía él, pero ahora mismo está un año en el paro. Este 30 de noviembre ya cumple un año de paro, igual está buscando. Sale a buscar, dice que deje el CV y le dicen que le van a llamar, pero no le llaman. Hoy día mismo salió de mañana y le dijeron que vaya a un curso y se fue. Y ahí están...a ver si se puede seguir adelante o no porque estamos pensando mejor volvernos, porque qué hacemos aquí sin trabajo e igual, los niños, mi hija mayor no se enseña, dice "mami, mándame, mándame" (Cecilia).

En efecto, es sumamente preocupante conocer que de todos los casos indagados, apenas dos padres de familia tienen trabajo.

"Y ahora la situación en la que estamos, pues han despedido a muchísima gente de allí de la empresa, han despedido a muchos y despidieron 8 y en el siguiente turno ya mi marido fue el elegido, o sea que está en el paro y bueno, le toca seguir" (Laura)

Mientras los hombres se han quedado sin trabajo, las mujeres mantienen sus puestos, aunque muchas veces con una reducción de jornadas o a través del mantenimiento de las mismas horas a cambio de menos dinero

"Bueno yo gracias a dios sigo trabajando, aunque nos han bajado un poco de horas porque me acuerdo hacía hasta 45 horas a la semana, ahora no, ahora sólo 22 y han bajado, han reducido los usuarios y a nosotros nos han reducido horas" (Lucía).

"La gente necesita trabajar y hay mucha demanda, entonces ahora...cuando vine, siempre estuve trabajando. Ahora mismo estoy en el paro, cobrando el paro y voy a hacer unas "horitas", pero separado. O sea, voy a hacer "horitas" dos veces por semana donde una abuelita, pero nada más. Ahora estoy en el paro, mi esposo igual, ya van a ser 3 meses que el jefe no le paga. A pretexto de la crisis. Por eso mi esposo ya no está trabajando, dice "para qué ir al trabajo si este no nos va a pagar" y haciendo el trabajo gratis tampoco. Entonces al ver que no le paga, ya no se ha ido a trabajar" (Cecilia). 
La decisión de volver se conecta con otros asuntos como las alternativas y posibilidades que se barajan en Ecuador, las deudas en España, el contar o no con ahorros, el apoyo de una red, la situación legal, etc.

\begin{abstract}
“Terminará, lo que pasa es que mi alternativa es regresarme, no es quedarme aquí. Mi única alternativa es regresarme, mientras más pronto, mejor. Si pudiera mañana me iría. Yo tengo otras perspectivas, a mí esto no me emociona. Ellos se quieren ir también. Allá tenemos más posibilidad, de posibilidades hay en cualquier lado y son mejores allá que aquí, no es lo mismo que es lo mismo que estar dependiendo de alguien que dependiendo de ti mismo. Un poco si mañana cualquier cosa pasa aquí, yo siempre he tenido la doble alternativa, he hecho cosas aquí y allá. Si tengo algo aquí es por ellos, si las cosas están mal allá, digo bueno, que al menos tengan dónde llegar y no lleguen como uno, con las manos vacías a empezar. La ventaja es que mis hijos tienen doble nacionalidad, todos tenemos, eso no nos tiene cerradas las puertas, viajamos siempre con pasaporte europeo. Vamos a cualquier lado, no tenemos problemas" (Jaime).
\end{abstract}

Aunque la idea regresar no es generalizada, parecería evidente que se convertirá en una opción para cada vez más familias. Este es un asunto al que se ha de prestar una atención especial porque, entre otras cosas, la partida representaría para los hijos una transformación en la organización familiar, una nueva ruptura y un cambio en las expectativas, planes y trayectorias escolares de los niños, niñas y jóvenes.

\title{
Conclusiones
}

En general, papás y mamás piensan que estudiar sí es importante, asocian el sacrificio familiar ligado a la migración a la oportunidad de que sus hijos e hijas participen en el sistema educativo español el cual es mirado como superior en la medida en la que aparenta ser menos polarizado que el ecuatoriano, en que los diplomas españoles tienen más valor que los del país de origen y en que es más "avanzado". En este sentido, papás y mamás proyectan el éxito del proyecto migratorio familiar en el éxito escolar de sus hijos/as cuyo cumplimiento se coloca casi de modo único sobre sus hombros.

Así mismo, existe la percepción de que el sistema educativo español no es excluyente y que los niños/as y jóvenes no reciben un trato discriminatorio por su origen. De hecho, padres y madres se refieren a la incorporación de sus hijos a la escuela en términos de una "adaptación" ligada a la sensación de que han sabido ajustarse al nuevo espacio, sus ritmos y particularidades. Por otro lado, la figura del profesor se asocia a la de autoridad de tal manera que la preocupación principal de papás y mamás tiene que ver con la noción de obligación la cual se relaciona al cúmulo de tareas que hacen fuera de la escuela. Se mide la eficacia o el aprendizaje de acuerdo a la cantidad de deberes que llevan a casa y lo contrario es interpretado como una señal de poca exigencia y despreocupación por parte de maestros y maestras. La representación que se tiene de los profesores se relaciona al esquema jerárquico maestro-alumno, se confiere autoridad y legitimidad a la figura del profesor al que se le debe respeto y obediencia. Sin embargo, si bien por un lado, la figura del profesor tiene peso y se espera que sea exigente, por otro, se señala que son los mismos chicos/as los responsables de su éxito o su fracaso. Esto acentúa cierta imagen de los profesores que es casi incuestionable y que se liga a su capacidad de exigir, pero a la que se le resta responsabilidad a la hora de rendir cuentas.

Por otra parte, se sostiene que la falta de información con respecto a la calidad, organización y funcionamiento de las instituciones de enseñanza en España repercute en cuestiones como la selección de la institución o en las expectativas escolares de los menores. Generalmente, las prácticas mencionadas dependen del capital escolar de los padres y madres, del tiempo del que disponen e incluso de la organización familiar a lo cual, en un contexto migratorio, ha de agregarse el factor de desconocimiento del nuevo medio en general y el escolar, en particular. 
En esta misma línea, se ha señalado que la mayoría de papás y mamás expresan el deseo de que sus hijos obtengan una formación que les permita alcanzar un status y posición social superior al suyo y el camino reconocido para alcanzar dicha meta es el académico. Ahora bien, el hecho de hacer una carrera o tener una profesión suele ser ambivalente pues puede significar varias cosas al mismo tiempo: trabajar pronto, obtener un título técnico o intermedio o ir a la universidad.

En cuanto a la participación de los progenitores en la institución, se ha sugerido que esta tiene lugar por medio de la asistencia esporádica o casi nula a las convocatorias de la escuela (como la escuela para padres, por ejemplo) o a través del control académico y disciplinar de los chicos por medio de encuentros puntuales con los tutores.

Por lo señalado hasta el momento, se puede decir que existen algunos elementos que cruzan las prácticas y los discursos de padres y madres sobre el contrato pedagógico. En primer lugar, la carga de trabajo y la organización familiar son factores que inciden en los tiempos y la calidad de la relación entre la familia y la escuela. En segundo lugar, habría que pensar que el hecho de no compartir necesariamente la cultura escolar, profesional y la clase de los otros con quienes deben interrelacionarse (autoridades, maestros, tutores, etc.) puede constituirse en una frontera entre la escuela y las familias. A esto habría agregar el hecho de que si son madres y padres migrantes, aquella condición muchas veces representa un estigma o una marca a la hora de relacionarse e interactuar en el espacio escolar/nacional. Por tanto, quizás es pertinente plantear que los discursos y las prácticas de los progenitores tienen lugar en una cultura de poder en la que el valor de cambio de sus capitales es percibido como menor e incluso inexistente.

Sostenemos que, según los resultados de este trabajo, la actitud de los progenitores hacia la escuela, en lugar de ser chocante o incompatible, le confiere legitimidad pues reafirma las bases en las cuales se asienta. En efecto, los discursos asientan la autoridad del profesor, la separación entre las familias y la escuela, la prevalencia de la cultura escolar sobre la falta de la misma, etc. Esto, lejos de reafirmar la percepción común de que existe una suerte de "choque cultural" entre los padres y madres migrantes y la escuela, más bien, indica todo lo contrario y sugiere nuevas preguntas y líneas de investigación dirigidas a colocar el centro de su atención en las instituciones escolares, la formación del profesorado, el sistema curricular y su estructura y por supuesto, en los mecanismos a través de las cuales considera o deja de considerar el papel de los padres y madres de familia, el reconocimiento de los conocimientos y saberes de los que son portadores o los canales a través de los cuales se lleva a cabo su participación.

Finalmente, es necesario enfatizar la idea de que, a pesar de que los discursos, expectativas y actitudes de los progenitores legimitan una institución educativa en crisis, no por ello la exclusión de la que creen escapar desaparece en el nuevo contexto. Más bien tiende a reproducirse. La escuela es un lugar en el cual se deposita una serie de valores y expectativas que no siempre se cotejan con las cifras y las realidades. Como se ha señalado, tanto en Ecuador como en España la tasa de deserción, los fracasos escolares y la segregación entre alumnos y alumnas en razón de género, clase social y etnicidad/origen ponen en duda la idea de una escuela homogénea y que realmente brinda las mismas oportunidades a todos y todas. 


\section{Anexo 1: descripción de los casos}

Paúl.

Nacido en Bucay (zona rural de la costa). Profesión: contador. Tiene 3 hijos. Llegó a España hace doce años, al año siguiente viajaron su esposa y sus dos hijos ( 5 y 6 años). Después de cinco años la familia retornó a Ecuador, estuvieron allí dos años y después volvieron a España. El tercer hijo de la pareja nació en España. Tiene estudios universitarios. En España está hipotecado y trabaja en una empresa.

\section{Lucía.}

Nacida en el Quinche (zona rural de la sierra). Estudió seis años y dejó la escuela para dedicarse a trabajar en el servicio doméstico. Se casó con Manuel y en el 2000 ambos viajaron a España, sus dos hijos se quedaron a cargo de su hermana y su familia. Los niños viajaron después de 7 años y llevan algunos meses en España. El no tiene trabajo, están hipotecados junto con varios familiares y su esposa se dedica a la limpieza.

\section{Manuel.}

Nacido en el Quinche (zona rural de la sierra). Estudió seis años y dejó la escuela para trabajar como carpintero. Se casó con Lucía y en el 2000 ambos viajaron a España, sus dos hijos se quedaron a cargo de su hermana y su familia. Los niños viajaron después de 7 años y llevan algunos meses en España. El no tiene trabajo, están hipotecados junto con varios familiares y su esposa se dedica a la limpieza.

\section{Laura.}

Nacida en Ibarra (ciudad de la sierra). Es bachiller. Viaja en el año 2000 y luego de cuatro meses logra reagrupar a su esposo y su hijo (5 años). Su esposo está en paro. El trabajaba en la construcción y ella en limpieza.

\section{Carmen.}

Nacida en Guayaquil (ciudad de la costa). Estudió ingeniería comercial. En 2000 viajó su esposo y a los cuatro años lo hizo ella junto con sus dos hijos (7 y 5 años). En España ha trabajado limpiando pisos y su esposo como electricista. Hoy en día, él está en paro.

\section{Cecilia.}

Nacida en Conocoto (zona urbana de la sierra). Estudió el bachillerato, era costurera y el esposo, también bachiller, era carpintero. En 1999 su esposo viajó a Italia y después de un tiempo a Madrid. Al año nueve meses viajó Cecilia y los niños se quedaron a cargo de los padres de ella. En el 2002 trajo a su hija (7 años) y el hermano menor (2 años) permaneció a cargo de los abuelos hasta el 2008. En España la pareja tuvo otra niña. Ella trabaja en labores de limpieza, pero actualmente no encuentra trabajo y él lleva un año en el paro. 


\section{Anexo 2: estructura del sistema educativo en Ecuador}

La educación preescolar tiene una duración de 1 año y está destinada para niños de cinco a seis años de edad. Los establecimientos de este nivel con recursos suficientes, pueden organizar un periodo anterior más. La educación preescolar no es obligatoria. La educación en el nivel primario comprende 6 grados, organizados en tres ciclos de dos años cada uno. La educación primaria es obligatoria y atiende a los niños a partir de los seis años de edad.

La educación del nivel medio comprende tres ciclos: básico, diversificado y de especialización. La educación en el ciclo básico comprende tres cursos de estudio, de un año lectivo cada curso, que completan la escolaridad obligatoria.

El ciclo básico inicia la formación del nivel medio en el que se promueve una cultura general de base y se desarrollan actividades de orientación que permiten al estudiante seleccionar la especialidad en el ciclo diversificado y lo habilitan para el trabajo. Se imparte en los colegios de ciclo básico o en el ciclo básico de los colegios de bachillerato.

El ciclo diversificado procura la preparación interdisciplinaria que permite la integración del alumnado a las diversas manifestaciones del trabajo y la continuación de estudios en el ciclo post-bachillerato o en el nivel superior. El ciclo diversificado está configurado por: a) carreras cortas post-ciclo básico, con 1 o 2 años de estudio; y, b) Bachillerato con 3 años de estudio.

Quienes aprueban el ciclo diversificado y las pruebas de grado correspondientes, reciben el título de Bachiller, con la indicación de la especialización respectiva.

El ciclo de especialización se realiza en los institutos técnicos y tecnológicos y está destinado a la capacitación de profesionales de nivel intermedio. El ciclo de especialización corresponde al post-bachillerato, con dos y/o tres años de estudio posteriores al bachillerato.

Existen dos tipos de centros de estudios superiores no universitarios: los Institutos Pedagógicos y los Institutos Técnicos Superiores. Los centros de estudio superiores no universitarios desarrollan carreras intermedias con dos o tres años de estudio post- bachillerato. Los planteles de post-bachillerato preparan profesionales de nivel intermedio y ofrecen una formación y capacitación científica y tecnológica que permite al estudiante incorporarse, en corto tiempo, al mundo del trabajo.

Las universidades y escuelas politécnicas otorgan títulos de licenciado, abogado, doctor y muchos otros que corresponden a especializaciones en el contexto de determinadas carreras profesionales de acuerdo con la carrera o especialización.

La escala de calificaciones es de 1 a 20, con las siguientes equivalencias: 20-19: actuación sobresaliente; 18-16: actuación muy buena; 15-14: actuación buena; 13-12: actuación regular; 11 o menos: actuación insuficiente.

(fuente: www.ibe.unesco.org) 


\section{Bibliografía}

Actis, W. 2005, "Ecuatorianos y ecuatorianas en España: "Inserción (es) en un mercado de trabajo fuertemente precarizado", en: Herrera, G. et al., (comp.) La migración ecuatoriana. Transnacionalismo, redes e identidades (pp.169-202), FLACSO / Plan Migración, Comunicación y Desarrollo, Quito.

ALISEI, FLACSO, CEPAM, CEPLAES. 2005, Tendencias y Efectos de la Migración en el Ecuador, ALISEI / FLACSO, Quito.

Blase, J. 2002, "Las micropolíticas del cambio educativo", en: Revista de Profesorado Currículum y Formación de Profesorado, 6 (1-2), pp.1-15.

Bourdieu, P. 1999, La miseria del mundo, Akal, Madrid.

Camacho, G. y Hernández. K. 2007, Memorias del I Seminario - Taller internacional: Familia, niñez y migración en el Ecuador, UNICEF / INNFA / CEPLAES, Quito.

Camacho, G. y Hernández, K. 2008, Diagnóstico de situación: Niñez y migración en el Ecuador, UNICEF / INNFA / CEPLAES, Quito.

CEPAL. 2002, Panorama Social de América Latina 2001-2002, CEPAL, Quito.

CEPAL-UNICEF. 2006, Boletín Desafios, No. 3, Agosto, CEPAL, Quito.

Esteves, A. 2008, "Introducción”, en: C. Arcos y B. Espinoza, Desafíos de la educación en el Ecuador: calidad y equidad, FLACSO, Quito.

Franzé, A. 2002, Lo que sabía no valía. Escuela, diversidad e inmigración. Madrid: Consejo Económico y Social, Comunidad de Madrid.

Franzé, A. 2003, "Las formas escolares del extrañamiento. Un estudio de los intercambios comunicativos en un contexto multicultural", en: Poveda, D. (coord.) Entre la diferencia y el conflicto: miradas etnográficas a la diversidad cultural en la educación, Universidad de Castilla-La Mancha, Ediciones de la Universidad de Castilla-La Mancha, España, pp.99-137.

Franzé, A; Jociles, M; Sánchez, J; Villaamil, F; Peláez, C; Cucalón, P; Calvo, A; y Sánchez, P. 2007, “La mediación de la cultura de origen en las concepciones y prácticas del profesorado de la ESO". Actas del IX Congreso Español de Sociología. Barcelona: Federación Española de Sociología, Federación Española de Sociología, Barcelona.

Gabinete de Estudios de la Federación Regional de Enseñanza de Madrid de CCOO. 2005, El alumnado inmigrante en la Comunidad de Madrid, CCOO, Madrid.

García, I. 2008, Herederos de la condición de inmigrantes: adolescentes y jóvenes en familias madrileñas de origen extranjero, tesis doctoral presentada en la UNED, Departamento de Sociología I.

García, J.A. y Moreno, I. 2002, La evaluación educativa. Cuadernos de Bitácora Madrid, 4, España, pp. 19-38.

Herrera, G. y Alexandra, M. 2002, Género y migración en la región Sur. Informe de investigación (mayo), FLACSO / Embajada de Holanda, Quito.

Herrera, G. 2005, Remesas, dinámicas familiares y estatus social. En N. Zúñiga (coord.), La migración: Un camino entre el desarrollo y la cooperación, Centro de Investigaciones para la Paz, Madrid, pp.149-162.

Herrera, G. 2005, Mujeres ecuatorianas en las cadenas globales del cuidado. En G. Herrera, C. Carrillo y A. Torres (comps.) La migración ecuatoriana. Transnacionalismo, redes e identidades, FLACSO / Plan Migración Comunicación y Desarrollo, Quito, pp. 281-305.

Jociles, M.I. 2007, Panorámica de la antropología de la educación en España: estado de la cuestión y recursos bibliográficos. Revista de antropología social, 16, pp.67-116.

Lagomarsino, F. 2005, ¿Cuál es la relación entre familia y migración? El caso de las familias de emigrantes ecuatorianos, en: Génova. En G. Herrera, C. Carrillo y A. Torres (comps.), La migración ecuatoriana. Transnacionalismo, redes e identidades, FLACSO / Plan Migración Comunicación y Desarrollo, Quito, pp. 335-361.

Lahire, B. 2000, Los orígenes de la desigualdad social. En: Marchesi. A y Hernández Gil. C, El fracaso escolar, Fundación por la modernización de España, Madrid, pp. 73-84.

Luna, M. 2006, La educación en los últimos años, Contrato Social por la Educación, en: http://www. contratosocialecuador.org.ec/home/index.php

Martínez, J. 2007, "Fracaso escolar, clase social y política educativa”, en: Revista El Viejo Topo, 238, España, pp. 45-49. 
Meñaca, A. 2005, "Ecuatorianas que viajaron. Las mujeres migrantes en la familia transnacional”, en: G. Herrera, C. Carrillo y A. Torres (comps.), La migración ecuatoriana. Transnacionalismo, redes e identidades, FLACSO / Plan Migración Comunicación y Desarrollo, Quito.

Moscoso, M.F. 2008, "Subjetividades infantiles, migración y escuela”, en: Iconos: Revista de Ciencias Sociales, 31, FLACSO, Quito, pp. 131-144.

Moscoso, M.F. 2009a, “Acerca del enfoque (auto) biográfico y la subjetivdad. El caso de los niños (ecuatorianos) en Alemania y España", en: Iconos:Revista de Ciencias Sociales, Flacso-Quito (en revisión), Quito

Moscoso, María Fernanda. 2009b, "Infancias transnacionales: aproximaciones etnográficas", en: Camacho, G. y Hernández, K. (comps.) Miradas transnacionales. Visiones de la migración ecuatoriana desde España y Ecuador, SENAMI-CEPLAES (en prensa), Quito.

Orozco, A. 2009, “Cadenas globales de cuidados: ¿Desvelando la agenda oculta del desarrollo? Andina migrante”, en: Boletín del sistema de información de migraciones andinas, 2, FLACSO, Quito.

Pedone, C. 2005, "Tú siempre jalas a los tuyos". Cadenas y redes migratorias de las familias ecuatorianas hacia España", en: G. Herrera, C. Carrillo y A. Torres (comps.), La migración ecuatoriana. Transnacionalismo, redes e identidades, FLACSO / Plan Migración, Comunicación y Desarrollo, Ecuador, pp.169-202.

Poveda, D. 2003, "La segregación étnica en contexto: El caso de la educación en Vallecas -Puente de Vallecas", en: Education Policy Analysis Archives, 11 (49). Disponible en http://epaa.asu.edu/epaa/v11n49 (Fecha descarga: 18 Septiembre 2009).

Poveda, D; Franze, A; Jociles, M; Rivas, A; Villaamil, F; Peláez, C; Sánchez, P. 2007, "La segregación étnica en la educación secundaria de la ciudad de Madrid: Un mapa y una lectura crítica”, II Congreso Internacional de Etnografia y Educación, Barcelona, 5-8 Septiembre.

Pribilsky, J. 2001, "Los niños de las remesas y traumas de la globalización”, en: Revista Ecuador Debate, 54, $127-154$.

Reyes, H. 2002, “QQué mismo es esa cosa llamada familia?: Esbozo de los nuevos paradigmas comprensivos”, en: Revista Ecuador Debate, 56, Quito.

UNESCO. 2004, Participación de las familias en la educación infantil latinoamericana. Santiago de Chile: Editorial Trineo.

Venegas, H. 2006, Educación de calidad para todas y todos. Una propuesta ciudadana para el ejercicio de derechos en el ámbito educativo, Cuadernos 5. Quito: Contrato Social por la Educación en el Ecuador.

Viteri, G. 2006, Situación de la educación en Ecuador, UNESCO / BID, Quito. 
